\title{
Cell death and inflammation - a dangerous but vital liaison
}

\section{Nieves Peltzer ${ }^{1}$, Henning Walczak ${ }^{1}$}

${ }^{1}$ Centre for Cell Death, Cancer and Inflammation, UCL Cancer Institute, University College London, 72 Huntley Street, London WC1E 6BT, United Kingdom

\begin{abstract}
The immune system has developed multiple ways to fight infection. Yet, it is constantly tasked with overcoming newly developing pathogenic mechanisms of resistance to host immunity. In most mammals, the stimulation of both, innate and adaptive immune receptors can result in gene activation and cell death induction by apoptosis and necroptosis. RIPK1 and RIPK3 are key mediators of necroptosis; however, new findings support their role in the regulation of cell death-independent proinflammatory signaling. Here, we discuss the biological functions of RIPK1 and RIPK3 and how they regulate cell death and inflammation as well as the interplay between them. Finally, we discuss recent advances in our knowledge of linear ubiquitination which, alongside RIPK3 and Caspase-8, exerts regulatory functions on RIPK1-mediated inflammation. Together, this review examines the complex interplay between RIPK1, RIPK3 and LUBAC which is important to regulate cell death and inflammatory signaling.
\end{abstract}

\section{Host defense against tissue damage}

Tissue damage, for instance as a consequence of breakdown of cellular membranes, is dangerous, not the least because it can cause infection; the same is obviously true the other way around. Consequently, many organisms can sense both, damage and pathogens, a feat achieved via so-called damage- and pathogen-associated molecular patterns (DAMPs and PAMPs) (see glossary), respectively. Molecular patterns associated with different forms of damage, or various pathogens, are recognized by a family of receptors referred to as pattern-recognition receptors (PRRs). PRRs are expressed by both, immune and non-immune cells. The mammalian PRR family consists of Toll-like receptors (TLRS), RIG-I-like receptors (RLRs), NOD-like receptors (NLRs) and DNA sensors such as DNA-induced activator of IFN (DAI, also known as ZBP1) and Cyclic GMP-AMP synthase (cGAS). Triggering of PRRs results in the activation of mitogen-activated protein kinases (MAPKs) and nuclear factor Klight-chain-enhancer of activated B cells (NF-kB) signaling, and subsequent induction of inflammatory cytokines and chemokines including, amongst others, tumor necrosis factor (TNF) and interleukin-1 $\beta$ (IL-1 $\beta$ ). Engagement of certain PRRs also results in the activation of interferon regulatory factor (IRF) 3 and IRF7 and subsequent induction of type I interferons $(\mathrm{IFNS})^{1}$. These cytokines play crucial roles in triggering the mammalian innate immune response by binding to their respective receptors, including TNF receptor (TNFR) superfamily 
(SF) members. In addition to their ability to further induce inflammatory mediators via MAPK and NF-кB activation, some TNFR-SF members, are known as death receptors (DRs). This includes TNFR1, CD95 (Fas/APO-1), death receptor 3 (DR3) and two different receptors for the TNF-related apoptosis-inducing ligand (TRAIL), TRAIL-R1 (DR4) and TRAIL-R2 (DR5). These receptors have a cytoplasmic death domain (DD) that allows them to transduce a regulated pro-death signal resulting in apoptotic or necroptotic cell death (see glossary) ${ }^{2,3}$. Apoptosis and necroptosis are tightly regulated processes that are executed by specialized proteins, such as Caspase-8, RIPK1, RIPK3 and MLKL 2, 3. The discovery of these factors has revolutionized the way we understand cell death and disease. We are, however, only starting to understand how these molecules are regulated and, importantly, the interplay between them, including how they regulate each other. Recent breakthrough investigation has not only made tremendous steps in understanding the roles of these molecules in cell death regulation but has also uncovered that they bear important non-death functions. These cell deathindependent functions are related to the regulation of inflammatory signaling, the battle against pathogen and the regulation of key developmental processes such as hematopoiesis. This review will explore the most recent findings on these topics and discuss future avenues for investigation.

\section{Signal transduction by death receptors}

The different signaling outputs downstream of DRs strongly rely on the many components of the signaling complexes that are formed upon DR engagement by their cognate ligands. For example, ligation of TNFR1 by TNF results in the formation of a membrane-bound signaling complex referred to as the TNFR1 signaling complex (TNFR1-SC) or complex I of TNFR1 signaling (Figure 1). Formation of the TNFR1-SC is initiated by the TNF-induced recruitment of the adaptor proteins TNFR1-Associated Via Death Domain (TRADD), the Receptor Interacting Protein Kinase 1 (RIPK1), TNF Receptor Associated Factor 2 (TRAF2 and/or TRAF5) and the E3 ubiquitin ligases cellular Inhibitor of Apoptosis (CIAP) proteins 1 and 2 $(\mathrm{CIAP} 1 / 2)^{4}$. TNFR1-SC-recruited CIAP1/2 ubiquitinate various components of the TNFR1-SC, including RIPK1 and CIAP1, enabling the recruitment of another E3 ubiquitin ligase, the Linear UBiquitin chain Assembly Complex (LUBAC), which exclusively generates linear, also referred to as methionine 1 (M1)-linked, ubiquitin chains on substrates, including RIPK1, TRADD and TNFR1 ${ }^{5,6}$. This highly ubiquitinated protein complex enables efficient recruitment and retention of the kinase complexes comprised of the Transforming growth factor- $\beta$-activated kinase 1 and TAK1-binding protein 2 and 3 (TAK1/TAB2/3) and the Inhibitor of nuclear factor $\kappa-B$ kinase subunits $\alpha, \beta$ and NF- $\kappa B$ essential modulator (IKK $\alpha / I K K \beta / N E M O$ ), with NEMO itself also being modified by M1-linked ubiquitin ${ }^{7}$. Recently, the non-canonical IKKs, TANK-Binding 
Kinase 1 (TBK1) and IKKE were identified to form part of the TNFR1-SC to which they are recruited by NEMO, via the adaptor proteins TRAF family member-associated NF-אB activator (TANK) and Nucleosome assembly protein 1 (NAP1), in a linear-ubiquitin-dependent manner in cancer cell lines and primary mouse embryonic fibroblasts (MEFs). Activation of TAK1/TAB2/3 and IKKa/IKK $/$ NEMO results in subsequent gene induction through activation of NF-KB and MAPK signaling (Figure 1).

Under certain circumstances, the stimulation of TNFR1 by TNF can also induce cell death in mammalian cells. In these cases, a cytoplasmic complex, called complex-II, is formed. This cell death-inducing complex originates from the TNFR1-SC and contains RIPK1 and/or TRADD to which the DD-containing adaptor protein Fas-associated DD (FADD) is recruited ${ }^{9}$, 10 (Figure 1). FADD brings caspase-8 to the complex which, upon recruitment-mediated activation, initiates apoptosis induction. However, complex-II-associated RIPK1 can also recruit and activate RIPK3 which triggers necroptosis execution ${ }^{11-13}$. Both, apoptosis and necroptosis are tightly regulated by the cellular FLICE-like inhibitory protein (cFLIP) $)^{14}$. All isoforms of cFLIP can form heterodimers with caspase-8 in complex II. The heterodimer between the long isoform of cFLIP (CFLIP L and Caspase-8 can cleave RIPK1 and RIPK3 and prevent necroptosis ${ }^{15}{ }^{16}$ but it is not clear whether this enzymatic activity is responsible for this functional effect.

In addition to ubiquitin ligases, various deubiquitinases (DUBs) are important in regulating the signals triggered by TNF, including CYLD (cylindromatosis) and TNF $\alpha$-induced protein 3 (A20) which are recruited to the TNFR1-SC where they regulate the gene-activatory and cell death-inducing output of TNF signaling (reviewed in ${ }^{17,}{ }^{18}$ ). CYLD-mediated cleavage of polyubiquitin chains has been shown to function as a negative regulator of NF-KB 19, 20 . However, the role of A20 in TNF-signaling is independent of its DUB activity since it was shown that $A 20$ binds and protects M1 chains from cleavage ${ }^{21}$. Thereby, A20 likely interferes with recruitment of IKK $\alpha / \beta / N E M O$ kinase complex by binding to linear chains generated in, for instance, RIPK1 and TNFR1 ${ }^{21}$. A20 and CYLD, however, have opposing roles on the regulation of cell death induction by TNF. Whereas A20 prevents cell death by protecting linear ubiquitin chains from degradation, CYLD cleaves them and sensitizes cells to TNF-induced death ${ }^{21}, 22$. Induction of cell death by CYLD is thwarted by caspase-8/CFLIPL-mediated cleavage $^{23}$. Furthermore, the DUB known as OTU deubiquitinase with LINear linkage specificity (OTULIN) regulates TNF signaling outcomes by modulating LUBAC function ${ }^{21,24,25}$ (Figure 1). This demonstrates the high level regulation of cell death and inflammation downstream of DRs, ubiquitination and deubiquitination events being prominent regulatory checkpoints. 
Cell death can be induced independently of death receptors by binding of intracellular bacterial, viral or host danger signals to NLRs (different inflammatory cell death pathways are reviewed in ${ }^{26}$ ). This results in the assembly of a multi-protein complex called inflammasome. The best characterized inflammasome complex contains NLRP3 and activates caspase-1, thereby inducing maturation IL-1 $\beta$ and IL-18 and cleavage of gasdermin D. Gasdermin D then drives cell death by pyroptosis by forming pores in the membrane which is accompanied by the release of inflammatory mature IL-1 $\beta$ and IL-18 $8^{27}$. Recent work has also revealed a role for caspase-8 in processing and activation of Gasdermin $D^{28-30}$.

\section{RIPK1 - the molecular switch between life and death}

It is now established that, whereas the scaffolding function (see glossary) of RIPK1 is protective, the kinase activity of RIPK1 is pro-death. Indeed, RIPK1 deficiency induces postnatal lethality in mice which is prevented by combined loss of RIPK3 and caspase-8, but not by their individual loss ${ }^{31,32}$. By contrast, mice that express a kinase-dead version of RIPK1 $\left(R i p k 1^{K 45 A}\right.$ or Ripk1 ${ }^{D 138 N}$ ) are viable and resistant to necroptosis-dependent LPS-induced hypothermia, TNF-induced shock or Vaccinia Virus infection ${ }^{33,34}$. This indicates that the kinase activity of RIPK1 is crucial to mediate necroptosis in mice in a variety of necroptosisinducing insults. Therefore, RIPK1 is a double-edged sword that can prevent, but also allow cell death, at least in mouse models (reviewed $\mathrm{in}^{35}$ ).

Posttranslational modifications on RIPK1 play a critical role in this functional switch by preventing RIPK1 from recruiting and activating RIPK3 at cell death complexes. For instance, RIPK1 phosphorylation at specific sites when present in the TNFR1-SC prevents its autophosphorylation (e.g. S166), recruitment to complex-II and cell death in human and mouse cells $^{36,37}$ (Figure 1). Likewise, ubiquitination of RIPK1 can play a key role in the regulation of cell death and inflammation (reviewed in ${ }^{35,38}$ ).

An acceptor site for K63 linkages on RIPK1 is K377, which was proposed to be crucial for optimal NF- $\mathrm{KB}$ activation and prevention of cell death since human and mouse cells bearing a K377R mutation in RIPK1 display attenuated induction of NF-кB and MAPK pathways and are sensitized to TNF-, poly-IC- and LPS-induced cell death in vitro ${ }^{38}$. Yet, the relevance of this ubiquitination site in vivo remains to be determined. Using MEFs derived from mice bearing a clAP1 mutation in the ubiquitin associated (UBA) domain (Ciap2 $2^{-C_{C} \text { Ciap1 }}{ }^{\text {UBAmut }}$ ), another report showed that the UBA domain of cIAP1, is required to repress RIPK1 autoactivation. This is achieved by cIAP1-UBA-mediated ubiquitination of several Ub-acceptor lysines on RIPK1 since Ciap2 $2^{--}$Ciap1 $1^{\text {UBAmut }}$ MEFs displayed fewer ubiquitinated lysines, which promoted its autoactivation ${ }^{39}$. In addition, clAP1-generated K48-linkages on RIPK1 target it for proteasomal degradation, consequently limiting its stability ${ }^{39}$. Therefore, in the absence of 
a functional UBA domain, an increased amount of RIPK1 molecules with fewer ubiquitinated lysines induces exacerbated TNF-mediated cell death.

In the last two years, several kinases that prevent RIPK1 auto-phosphorylation have been identified (reviewed $\mathrm{in}^{40}$ ). The canonical kinases IKKa and IKK $\beta$ phosphorylate RIPK1 at several sites in the TNFR1-SC, thereby preventing its transition to complex II as demonstrated using MEFs deficient for each individual kinase or by IKKa/ $\beta$ inhibition ${ }^{41}$. The non-canonical IKKs TBK1 and IKKE also phosphorylate RIPK1 and this activity is required to prevent TNFinduced RIPK1 kinase activity-dependent cell death in vitro and in vivo ${ }^{8,42}$. This was evidenced by the fact that MEFs lacking TBK1 were sensitized to TNF-induced cell death which was prevented by treatment with a RIPK1 kinase inhibitor. In addition, whereas TBK1 inhibition sensitized mice to TNF-induced shock, expression of kinase-dead instead of wildtype RIPK1 prevented embryonic lethality of $T b k 1^{-/}$mice ${ }^{8,42}$ (Table 1). Although not recruited to the TNFR1-SC, the p38 MAPK target, MAP kinase-activated protein kinase 2 (MK2) phosphorylates RIPK1 at S321 and S336 and might constitute a secondary checkpoint in the control of RIPK1-mediated cell death, given that the mere phosphorylation of RIPK1 by MK2 is not strictly required to prevent TNF-induced cell death but only upon depletion of clAP1/2 or TAK1, which was shown in primary murine cells either treated with pharmacological inhibitors or in genetic models of cells lacking RIPK1 or MK2 ${ }^{43-45}$ (Figure 1).

The kinases that control RIPK1 auto-phosphorylation cannot substitute for each other, i.e. when only one of these distinct cell death checkpoints fails to operate properly, TNF induces cell death ${ }^{81-45}$ (Figure 3a). It is tempting to speculate that TNF signaling may serve the purpose of a 'litmus test' which might probe for proper immune signaling, checking whether TNF is capable of inducing the activation of MAPKs, the NF-KB-activating kinases IKK $\alpha$ and

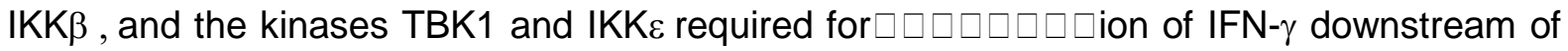
several immune receptors, albeit not TNFR1 ${ }^{1,8}$. If TNF signaling were to fail this litmus test in a given cell, TNF would induce its death and, thereby, the release of a multitude of DAMPs ${ }^{8}$, ${ }^{41-45}$. In doing so, TNF, previously referred to as the 'fire alarm of the immune system' ${ }^{\prime 4}$, would chime the big ben of fire alarms.

\section{RIPK3 - killing me... not so softly}

Necroptosis is induced as a result of the formation of a hetero-amyloid complex between RIPK1 and RIPK3 that associates via their respective RIPK homotypic interaction motif (RHIM), called the necrosome ${ }^{11,13,47}$. The kinase activities of both RIPK1 and RIPK3 are required for canonical necroptosis induction (Figure 1) ${ }^{33,34,48}$. RIPK3, in turn, phosphorylates and, thereby, activates the pseudokinase mixed lineage kinase domain-like $(M L K L)^{49,50}$. However, certain PRRs, such as TLR3 and TLR4, can drive RIPK3 activation via the adapter 
protein TIR-domain-containing adaptor-inducing IFN- $\beta$ (TRIF) and the DNA-induced activator of IFN (DAI, also known as ZBP1) ${ }^{51,52}$, two additonal RHIM-containing proteins (Figure 1).

Spontaneous necroptosis is observed in mutant mice lacking the RHIM domain of RIPK1, resulting in embryonic lethality (Table 1$)^{37,53}$. This aberrant necroptosis is mediated by DAI and, to a lesser extent, also by TRIF. These findings were genetically demonstrated by loss of DAI in mice, which rescued Ripk1 $1^{\Delta R H I M}$ mice from lethality ${ }^{37}$. Furthermore, deficiency in RIPK3 or DAI allowed Ripk1 ${ }^{-/}$Casp- $8^{-/-}$mice to be born, demonstrating that RIPK1 could serve an essential survival function by interfering with aberrant RIPK3/DAl-induced lethal necroptosis ${ }^{31,32,37 .}$

The mechanism of activation of DAI/RIPK3-mediated necroptosis under physiological conditions remains to be determined. DAI has long been thought of as a specific sensor of dsDNA, yet, endogenous RNA was recently found capable of activating DAI. This was demonstrated using MEFs infected with murine cytomegalovirus (MCMV). In this context, cell death induction upon infection required RNA synthesis but not viral DNA replication and DAI was found to directly bind to RNA via its Z-binding domain (ZBD) ${ }^{54}$. Supporting the notion of DAI as an RNA sensor, another report showed that DAI-deficient mice are susceptible to lethal infection by Influenza A virus (IAV) ${ }^{55}$. These studies indicate that RIPK1 may prevent noncanonical necroptosis induced by endogenous RNA, challenging the role of DAl as an exclusive DNA sensor ${ }^{56}$.

In essence, the more we learn about necroptosis execution, especially about the role of RIPK3 in this process, the more we come to realize that its regulation is more complex than originally anticipated. There are several open questions concerning the interactions of different RHIMdomain-containing proteins and how they regulate necroptosis (see "outstanding questions"). Although it now appears that RHIM-dependent oligomerization of RIPK3 is a common execution step in necroptosis induction, further and robust investigation is required to understand the nature of RIPK3 activation.

\section{MLKL - the key to membrane opening}

Once RIPK3 has been activated it undergoes a conformational change that induces its autophosphorylation, enabling the phosphorylation and activation of MLKL ${ }^{57-60}$. Activation of MLKL results in its recruitment to the plasma membrane where it can induce the formation of pores and the release of cellular content, including ions, leading to deleterious osmotic pressure ultimately resulting in disruption of membrane integrity. The mechanism of MLKL execution of necroptosis is still debated but it is believed that the pseudokinase interacts with phosphatidylinositol phosphates (PIPs) in the membrane and oligomerizes therein as 
demonstrated by crosslinking and oligomerization assays as well as lipid/protein coprecipitations under necroptotic conditions ${ }^{58,61}$. Moreover, a recent report described the MLKL channel as an octamer that is formed by pre-assembled tetramers; these MLKL tetramers were thought to form within the necrosome and to be released before or during translocation to the plasma membrane ${ }^{62}$.

Activation of MLKL, however does not represent a point-of-no-return in the execution of necroptosis ${ }^{63-65}$. It has been shown that the endosomal sorting complexes required for transport (ESCRT) machinery (see glossary), which accumulates at MLKL-damaged sites in the membrane, can facilitate membrane repair and, consequently, survival. Presumably, the ESCRT machinery, by localizing to the site of damage in the plasma membrane, enables the release of such damaged membrane domains and, with them, accumulated MLKL, in the form of membrane-surrounded bubbles ${ }^{63-65}$. Indeed, silencing of ESCRT components sensitized cells to necroptosis following activation of RIPK3 or MLKL by expression of the dimerizers RIPK3-2Fv or hMLKL ${ }^{1-181}-2 \mathrm{Fv}^{56-58}$. These studies suggest that, if the MLKL-activating stimulus is sufficiently powerful to allow the pore-forming activity of activated MLKL to surpass the repair activity of the ESCRT pathway, the cell might undergo necroptosis ${ }^{63-65}$. It appears there is still much to be discovered regarding MLKL regulation and the mechanisms of necroptosis execution and it will be exciting to learn about posttranslational modifications of MLKL (e.g. ubiquitination), as these may play a role in regulating the outcomes of necroptosis.

\section{RIPK3 - now going apoptotic}

Other than a key inducer of necroptosis, RIPK3 can also regulate apoptosis. A role of RIPK3 in the regulation of apoptosis is prominent during viral infection. For instance, mice constitutively lacking RIPK3 or both MLKL and FADD, but not MLKL alone, are more susceptible to Influenza A virus (IAV) infection than their wild-type counterparts. This reveals an important role for RIPK3-mediated apoptosis in antiviral immunity ${ }^{66}$.

Under sterile conditions, RIPK3 can also induce apoptosis. A few years back, two individual studies reported that different mutations leading to the abrogation of RIPK3 kinase activity harbored opposing phenotypes in mice. Whereas Ripk $3^{K 51 A / K 51 A}$ mice were born and resistant to necroptosis stimuli, Ripk3 ${ }^{D 161 N / D 161 N}$ mice were embryonically lethal due to aberrant RIPK1 and caspase- 8 dependent apoptosis since this lethality was prevented by concomitant deletion of RIPK1 and caspase-8 (Table 1) ${ }^{33,48}$. In addition, high concentrations of two specific RIPK3 inhibitors, GSK'843 and GSK'872, allosterically activated RIPK3, triggering the formation of a FADD/RIPK1/Caspase-8 platform that ultimately killed murine cell lines and MEFs via apoptosis ${ }^{48}$. These findings indicated that conformational changes caused by the RIPK3 D161N mutation enabled RIPK3 to induce apoptosis (Figure 2a and b). 
A recent report extended on these findings and provided important insight into the function of the kinase domain of RIPK3 ${ }^{62}$. Ripk $1^{-/}$mice, which normally survive embryogenesis, die at late gestation during embryogenesis when crossed to Ripk $3^{+/ D 161 N}$ mice (Ripk1 $1^{-/}$Ripk3 $3^{+/ D 161 N}$ mice) (Table 1) ${ }^{67}$. This finding, together with the observation that heterozygosity of Ripk3 does not induce embryonic lethality in RIPK1-null mice ${ }^{31,32}$, indicates that the D161 mutation might determine a conformational change that, in the absence of RIPK1, causes the activation of the wild-type copy of RIPK3, resulting in exacerbated necroptosis (Figure 2a). Although this remains to be directly shown, this study provides compelling evidence that whilst the D161N mutation of RIPK3 abrogates its kinase activity, it also locks RIPK3 in a configuration that favors homodimerization via the kinase domain and allosteric activation of wild-type RIPK3. Consistent with this model, a mutation of the homodimerization interface of RIPK3, R69H, abolishes the allosteric activation otherwise afforded by the D161N mutation, demonstrating the importance of the scaffolding function of RIPK3 in cell death regulation ${ }^{67}$.

Lastly, MEFs lacking RIPK3 and treated with Smac mimetics or TAK1 inhibitors were protected from TNF-induced apoptosis. However, cells expressing kinase-dead (K50A) or RHIMdeficient RIPK3 were only partially protected. This means that in conditions of cIAP1/2 or TAK1 depletion, which induce RIPK1-dependent cell death, RIPK3 contributes to caspase-8 activation independently of its kinase activity or RHIM domain ${ }^{68}$. This again implies a scaffolding role for RIPK3 in apoptosis regulation (Figure 2c). Together, these studies support the notion that the kinase domain of RIPK3 also harbors scaffolding functions and that, together, these two functions may regulate apoptosis and necroptosis. Yet, future studies are needed to provide further mechanistic insight on these distinct roles of RIPK3.

Nonetheless, despite the decisive roles for RIPK1, RIPK3 and their respective kinase activities in the induction of cell death, they also exert cell-death-independent functions.

\section{The life of RIPs - it's not all about death}

It is well established that, at least in certain cell types, RIPK1 is involved in NF-кB-induced gene activation and production of various proinflammatory cytokines. In addition, RIPK3 has been shown to be involved in inflammation also independently of cell death as discussed in this section.

In a recently reported mouse model expressing a catalytically-inactive mutant of RIPK3 containing a four-amino-acid deletion (Ripk $3^{\Delta 20-23}$ mice), which phenotypically resembles a kinase-dead mutant that does not affect homodimerization (see discussion above), FADDdeficient mice were rescued from embryonic lethality (Table 1$)^{69}$. This demonstrated that catalytically-inactive RIPK3 could interfere with aberrant necroptosis triggered when FADD is 
absent ${ }^{69}$. However, unlike Fadd ${ }^{-/-}$Ripk $^{-/-}$mice, which are viable, Fadd ${ }^{-1}$ Ripk3 $3^{\Delta 20-23}$ mice succumb at birth due to increased production of inflammatory cytokines, such as TNF, IL-1 $\beta$ and IL-6, in the intestine ${ }^{69}$. Whether the inflammation in Fadd ${ }^{-1}$ Ripk $3^{\Delta 20-23}$ mice is due to a function of FADD that requires the kinase activity of RIPK3 or due to a gain-of-function of the RIPK3 mutation (unleashed in the absence of FADD) remains to be determined. Nevertheless, this result shows that the kinase activity of RIPK3 can regulate proinflammatory signaling independently of necroptosis.

Both RIPK1 and RIPK3 have also been shown to promote TRIF-requiring but MyD88independent cytokine production (TNF, CCL3, CCL4, GM-CSF and IL-6) by LPS upon caspase-8 inhibition in vitro, since bone marrow derived macrophages (BMDMs) deficient for RIPK1 or RIPK3 were unable to promote cytokine release in response to LPS plus zVAD, a pan caspase inhibitor ${ }^{70}$. Of note, cytokine release was not affected in MLKL-deficient BMDMs, indicating that RIPK1 and RIPK3 can enable macrophages to mount an inflammatory response independently from their roles in MLKL-dependent necroptosis ${ }^{70}$. Along these lines, LPS/ZVAD-induced type I IFN production in BMDMs by the TLR4 pathway requires the kinase activities of both, RIPK1 and RIPK3 ${ }^{71}$. In addition, enhanced IFN- $\beta$ synthesis was observed after challenge with attenuated mutant strains of Yersinia pseudotuberculosis and Klebsiella pneumoniae upon caspase inhibition. This was again strictly dependent on the kinase activities of RIPK1 and RIPK3 ${ }^{71}$. In-vivo injection of non-cytotoxic doses of LPS in mice also led to a RIPK1- and RIPK3-dependent acute inflammatory response and type I IFN production $^{70,71}$. However, in this in-vivo situation, caspase inhibition was not required, since acute inflammation was observed upon LPS treatment alone. This might be due to a limited expression of caspase-8 by BMDMs per se in response to LPS, although this remains to be assessed $^{71}$. In contrast, in another study, loss of RIPK3 or of the kinase activity of RIPK1 had no impact on the response of mice to LPS-induced sepsis $^{72}$. Although this differential response could be due to the varying doses of LPS used in the different studies, further investigation is required to determine the exact roles of RIPK1 and RIPK3 in LPS responses in vivo.

Similarly to how RIPK1 and RIPK3 mediate acute inflammation, they can also play important roles in fighting infection. For example, RIPK1 kinase activity was shown to be required to fight Yersinia pseudotuberculosis by promoting apoptosis and cytokine production by hematopoietic cells ${ }^{73}$. Studies involving RNA viral infection have also shown that RIPK3deficient mice are more susceptible to infection by influenza A virus (IAV) than wildtype controls $^{66,74-76}$. The role of RIPK3 in this context might be due to both RIPK3-mediated apoptosis and necroptosis, as mentioned previously. However, the authors show RIPK3 interaction with the mitochondrial antiviral-signaling protein (MAVS), an adaptor in RLRS signaling platforms, and decreased IFN- $\beta$ production. Yet, deficiency of RIPK3 in BMDMs had 
no effect on necroptosis induction upon IAV infection in $\mathrm{BMDMs}^{74}$. This evidence suggests that RIPK3 might interfere with RIPK1-MAVS interaction, thereby limiting IFN- $\beta$ production in BMDMs independently of necroptosis. The authors also showed that RIPK3-deficient BMDMs displayed impaired Protein Kinase $R$ (PKR) signaling as detected by decreased phosphorylation of PKR and its downstream target phospho-elF2 $\alpha$. This implies that RIPK3 can induce activation of the PKR pathway in BMDMs, stabilizing Ifnb (IFN- $\beta$ ) transcripts ${ }^{74}$. Therefore, although RIPK3 can dampen the production of IFN- $\beta$ downstream of RLR signaling, it can also stabilize IFN- $\beta$ mRNA, thereby providing an IFN- $\beta$ response that appears to be sufficient to fight viral infection ${ }^{74}$.

Another study reported that RIPK3 could restrict West Nile virus (WNV)-induced encephalitis in a cell death-independent manner. Specifically, whereas RIPK3-deficient mice exhibited enhanced mortality upon WNV infection compared to wild-type mice, MLKL- or MLKL/caspase-8-deficient mice were unaffected, implicating a cell death-independent role of RIPK3 in this process ${ }^{77}$. The authors further demonstrated that RIPK3-deficient cortical neurons displayed impaired neuronal chemokine and cytokine production, such as CCL2 and CXCL10, upon WNV infection, poly(I:C) or LPS ${ }^{77}$. This indicates that RIPK3 is crucial for several TLRs to induce the secretion of proinflammatory cytokines. Thus, this work implicated RIPK3 in the regulation of immune responses in the central nervous system (CNS) ${ }^{77}$, but its exact functions warrant further investigation.

From another angle, RIPK3 has been proposed to be involved in the activation of inflammasomes ${ }^{78}$. Depletion of clAP1/2 in BMDMs or BM derived dendritic cells (BMDCs) by Smac mimetics induced activation of caspase-1 and secretion of IL-1 $\beta$. Moreover, deletion of RIPK3 interfered with this process after LPS treatment ${ }^{79}$. Another report additionally showed that caspase-1 and IL-1 $\beta$ activation in $M / k^{l^{-1}}$ BMDM was similar to that in WT cells ${ }^{80}$. Together, these studies suggest that RIPK3 is required for inflammasome activation independently of necroptosis induction. Consistent with in-vitro experiments, IL-1 $\beta$-dependent autoantibodymediated arthritis is exacerbated in cIAP1/2-null mice and it is counteracted by deletion of $\mathrm{RIPK}^{79}{ }^{70}$. Furthermore, deficiency in the DUB A20 triggers LPS- and poly(I:C)-induced IL$1 \beta$ maturation in BMDMs which was prevented by treatment with the RIPK1 kinase inhibitor Necrostatin-1s or by constitutive loss of RIPK3 ${ }^{81}$ (Table 1). The authors show that ubiquitin linkages on pro-IL-1 $\beta$ are increased in the absence of $A 20$ and that this ubiquitination was prevented in the absence of RIPK3, implying that A20-dependent IL-1 $\beta$ deubiquitination requires RIPK3. Together, these studies indicate that RIPK3 can promote NLRP3 inflammasome activation and IL-1 $\beta$-mediated inflammatory responses. In addition, they suggest that the NLRP3 inflammasome can be controlled by ubiquitination events which, in turn, are tightly regulated by RIPK1 and RIPK3. Furthermore, RIPK1 and RIPK3 appear to be 
required for RNA virus-induced activation of the NLRP3 inflammasome since RIPK3 deficiency or Necrostatin-1s treatment in BMDMs infected with vesicular stomatitis virus (VSV) interfered with inflammasome formation ${ }^{75}$. Although the RNA sensor that drives RIPK1/RIPK3dependent NLRP3 activation is unknown, a proposed mechanism suggests that the mitochondrial protein GTPase Dynamin related protein 1 (DRP1) might be involved in this process since depletion of DRP1 from murine BMDMs also interfered with inflammasome assembly. In addition, RIPK3 deficiency and RIPK1 inhibition prevented DRP1 activation as well as generation of reactive oxygen species (ROS) from mitochondria in infected cells. Therefore the authors propose that RIPK1/RIPK3 might activate DRP1 which could in turn promote the release of $\mathrm{ROS}^{75}$.

Collectively, these reports implicate RIPK1 and RIPK3 in innate immunity against pathogens, importantly in a manner that is not solely dependent on cell death regulation but also appears to involve cell death-independent proinflammatory signaling.

\section{Control of RIPK1-mediated proinflammatory signaling}

When examining the roles of RIP kinase proteins, reports have indicated that RIPK1 can play a pivotal role in emergency hematopoiesis (i.e. engraftment following BM transplantation, see glossary $)^{31}$. Although fetal hematopoiesis in Ripk $1^{-1-}$ mice is normal and hematopoietic progenitors are unaltered at birth, fetal BM progenitors lacking RIPK1 have impaired capacity to self-renew and to repopulate the BM of lethally irradiated mice ${ }^{47}$. Loss of RIPK1 from the hematopoietic compartment results in cell death in the spleen, the thymus and the BM and a decrease in hematopoietic stem and progenitor cells (HSPC). These defects appear to be partly mediated by RIPK3-dependent necroptosis since dying cells that were negative for cleaved caspase-3 were observed in the RIPK1-deficient BM and spleen and full loss of RIPK3 prevented this ${ }^{82}$. However, hematopoietic precursors deficient in both RIPK1 and RIPK3 have been shown to lack long-term multi-lineage-repopulating activity; the mechanism for this has

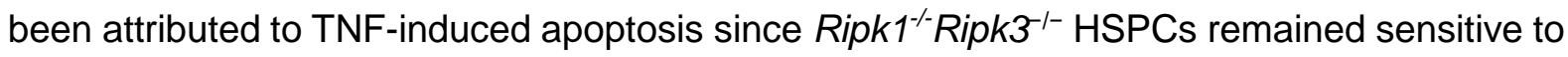
TNF-induced apoptosis in vitro ${ }^{82}$. These studies are relevant in that they indicate that RIPK1 is required for the integrity of major hematopoietic organs and emergency hematopoiesis in a process that depends on cell death, at least in mice.

Another study has shown that embryos which lack heme-oxidized IRP2 ubiquitin ligase 1 (HOIL-1), one of the two essential LUBAC components, together with caspase-8 and RIPK3

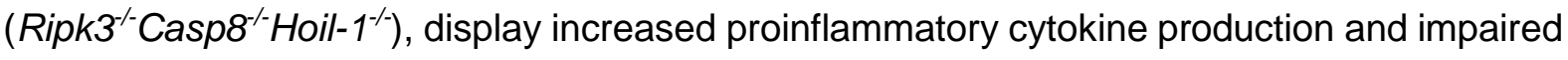
fetal hematopoiesis, as demonstrated by a dramatic decrease in hematopoietic progenitors ${ }^{83}$, 84 (Table 1). Of relevance, proinflammatory cytokines and hematopoietic defects were prevented upon removal of RIPK1. However, these defects were not observed in mice lacking 
HOIL-1, caspase-8 and MLKL, which suggests that these defects are independent of cell death induction. Thus, the absence of caspase- 8 and LUBAC function uncovers an essential function of RIPK3 in preventing RIPK1 from interfering with normal fetal hematopoiesis. How RIPK1 unleashes uncontrolled cytokine production and whether LUBAC and RIPK3 cooperate to counteract this activity warrants further investigation.

Nevertheless, based on currently available genetic models, some speculation can be made in this regard. For instance, since mice deficient in both caspase-8 and RIPK3 do not have impaired hematopoiesis that would cause embryonic lethality, LUBAC appears to be sufficient to keep RIPK1 in check to ensure proper hematopoiesis during embryogenesis. If this were true, it would indicate that LUBAC and RIPK3 might independently prevent aberrant RIPK1 signaling in the absence of caspase-8. However, deletion of caspase-8 alone can trigger enhanced inflammatory cytokine production in the absence of RIPK3 in mice, subsiding until birth, meaning that caspase-8 deficiency in itself can also promote deregulation of proinflammatory signaling ${ }^{85}$. Deletion of RIPK1 prevents this inflammatory output demonstrating that the inflammatory phenotype in $\mathrm{Ripk}^{-{ }^{-} \mathrm{Casp}} 8^{-{ }^{-}}$mice is a result of aberrant RIPK1 signaling ${ }^{85}$. Since deregulated cytokine production in Ripk $3^{-/-} \mathrm{Casp}^{-{ }^{--}}$mice does not

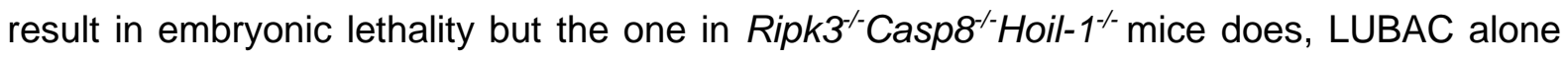
may be able to restrict aberrant RIPK1-mediated signaling to a degree that is compatible with survival (Figure 2b). However, in order to maintain optimal regulation of RIPK1, it is likely that the three components, LUBAC, caspase-8 and RIPK3, act in concert rather than independently of each other.

Studies performed on mice with mutations in OTULIN confirm a role for linear ubiquitination, caspase-8 and RIPK3 in regulating RIPK1-mediated signaling during embryogenesis. Hypomorphic (W96R, D336E mutations or Otulin ${ }^{\text {gumby }}$ mice) or catalytically inactive OTULIN (C129A mutation) resembles LUBAC deficiency, as it results in embryonic lethality due to defective vascularization in mice ${ }^{24,25,86}$. Indeed, vascular defects in Otulin ${ }^{\mathrm{C129A}}$ mice have been demonstrated genetically to be caused by exacerbated cell death as co-ablation of RIPK3 and caspase-8 normalized vascularization ${ }^{25}$. Although the vascular defects in Otulin ${ }^{\text {gumby }}$ mice were originally attributed to aberrant Wnt signaling, the role of cell death has not been investigated ${ }^{86}$ (Table 1). At face value, the fact that OTULIN deficiency virtually phenocopies LUBAC deficiency in mice is counterintuitive, because OTULIN was originally thought of as a negative regulator of LUBAC $^{86}$. However, it has been demonstrated that deficiency in OTULIN or in its activity can result in aberrantly increased linear ubiquitination of different LUBAC components prior to TNFR1-SC engagement and that this interferes with effective LUBAC recruitment to the TNFR1-SC in human cells ${ }^{21}$. These findings were later confirmed in murine cells ${ }^{25}$. Consequently, this creates a LUBAC hypomorph that cannot be recruited to signaling 
complexes and act in them appropriately ${ }^{24,25}$. Similar to LUBAC deficiency, Ripk3 ${ }^{-/}$Casp $8^{-/-}$ Otulin ${ }^{C 129 A}$ mice succumb after birth due to aberrant production of type I IFNs ${ }^{25}$. Loss of one copy of RIPK1 normalized IFN production and rescued these mice from postnatal lethality, implicating RIPK1-mediated signaling as responsible for aberrant inflammation and lethality in these mice ${ }^{25}$.

Collectively, these results show that RIPK3, caspase-8 and linear ubiquitination are important to block RIPK1-mediated cell-death-independent proinflammatory signaling during embryogenesis. It therefore appears that, similar to the regulation of RIPK1-mediated cell death, the non-cell-death aspects of RIPK1 signaling are placed under a stringent, triple control mechanism, namely one that relies on LUBAC, caspase-8 and RIPK3. However, unlike the triple control of RIPK1-mediated cell death, where a cell can die when any of the three kinases IKKa/ $\beta$, TBK1/IKKE or MK2 fails ${ }^{8,41-45}$, in the case of the non-cell-death function of RIPK1 signaling, either one of the three control mechanisms is sufficient to prevent RIPK1 from exerting signaling that is lethal for the organism (Figure $\mathbf{3 a}$ and $\mathbf{b}$ ).

\section{Concluding remarks}

During the past 10 years, significant steps towards the understanding of different programmed cell death pathways triggered by members of the TNFR-SF and PRRs have been made. Although several questions remain unanswered (see "outstanding questions"), this research has yielded the identification of key players of various programmed cell death pathways, the discovery of cell-death-driven inflammation and, based thereupon, the realization of new exciting perspectives to putatively target different forms of programmed cell death for the treatment of a variety of human diseases. At the same time, it is becoming increasingly clear that the very same players of these cell death pathways, including RIPK1, RIPK3, cIAP1/2, LUBAC and caspase-8, have important functions beyond their roles in cell death signaling. Current evidence suggests that these cell-death-independent functions are primarily related to the regulation of proinflammatory cytokine production. Moreover, these functions and outputs need to be carefully considered when seeking therapeutic intervention that perturbs one or more of these pathways; caution should be taken when attempting to inhibit any of these components with the aim of preventing pathological cell death and ensuing inflammation.

It is important to highlight that our increased understanding of the regulation of cell death and inflammation and of their interdependency in the form of the discovery of cell-death-driven inflammation, may prove crucial for the provision of effective treatments for patients suffering from auto-inflammatory disorders arising as a consequence of mutations in genes encoding, e.g. NEMO, A20, OTULIN, the different LUBAC components, TBK1, and RIPK1. Ultimately, 
this line of research will also hopefully lead to the discovery of more effective therapeutic options for patients with other chronic inflammatory, autoimmune or neurodegenerative diseases. It will be exciting to follow future research that aims to further elucidate the mechanisms and biology of these complex signaling pathways. 
Key Table, Table 1. Overview of mouse phenotypes bearing gene mutations in cell death regulators.

\begin{tabular}{|c|c|c|c|c|}
\hline \multirow[t]{2}{*}{ Genotype } & Phenotype & \multicolumn{2}{|c|}{ Restored phenotype } & \multirow[t]{2}{*}{ Reference } \\
\hline & Spontaneous & Partial & Complete & \\
\hline \multirow[t]{2}{*}{ Casp8 $8^{-/-}$} & $\begin{array}{l}\text { Embr. lethal E10.5 } \\
\text { Excessive cell death }\end{array}$ & Tnfr1 $^{-/}(\mathrm{E} 17.5)$ & $\begin{array}{l}\text { Ripk3/-- } \\
\text { MlkI--- }^{-1}\end{array}$ & $32,87-90$ \\
\hline & $\begin{array}{l}\text { Proinflammatory } \\
\text { phenotype }\end{array}$ & Ripk3\%- & Ripk3/-Ripk1 ${ }^{-/-}$ & 85 \\
\hline Fadd $^{-/-}$ & $\begin{array}{l}\text { Embr. lethal E10.5 } \\
\text { Cardiovascular } \\
\text { defects }\end{array}$ & & $\begin{array}{l}\text { Ripk3\%- } \\
\text { Ripk1\%- }\end{array}$ & $32,88,91$ \\
\hline Ripk1\%- & $\begin{array}{l}\text { Perinatally lethal } \\
\text { Multiorgan cell death } \\
\text { and inflammation }\end{array}$ & 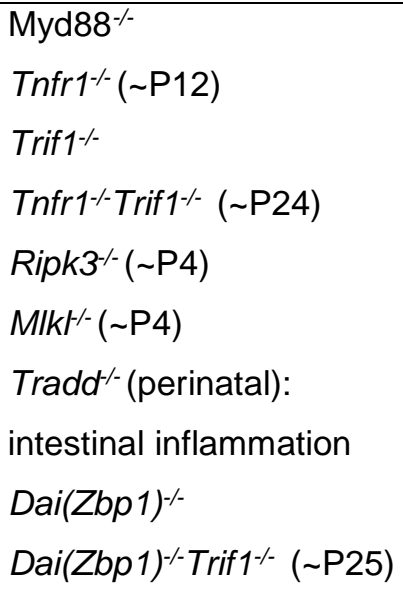 & 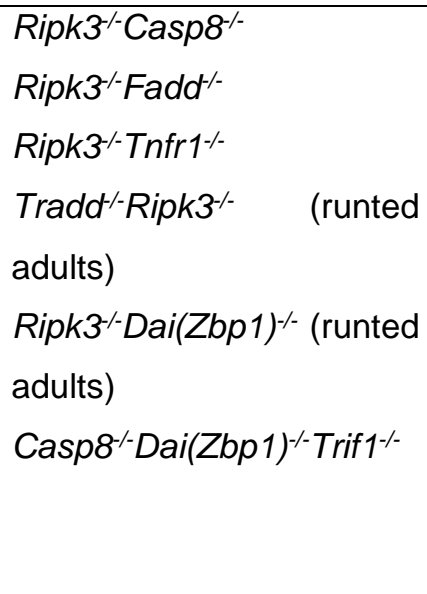 & $31,32,37,53,92,93$ \\
\hline Ripk3/-- & Viable & & & 11,12 \\
\hline$M \mid k^{-/-}$ & Viable & & & 49 \\
\hline Ripk1 $^{\text {K45A }}$ & Viable & & & 94 \\
\hline Ripk1 ${ }^{D 138 N}$ & Viable & & & 33,34 \\
\hline Ripk3 ${ }^{K 51 A}$ & Viable & & & 48 \\
\hline Ripk3 $3^{D 161 N}$ & $\begin{array}{l}\text { Embr. lethal E11.5 } \\
\text { Excessive apoptosis }\end{array}$ & $\begin{array}{l}\text { Casp8 }^{+-} \text {(E15.5) } \\
\text { Ripk1 }^{+/-}(\mathrm{E} 18.5)\end{array}$ & Ripk1\%-Casp8 $8^{-/-}$ & 33 \\
\hline $\begin{array}{l}\text { Ripk3+/D161N } \\
\text { Ripk1 }^{--}\end{array}$ & $\begin{array}{l}\text { Embr. lethal E18.5 } \\
\text { Excessive } \\
\text { necroptosis }\end{array}$ & & & 67 \\
\hline Ripk3 $^{\Delta 20-23}$ & Viable & & & 69 \\
\hline Ripk3 $^{\Delta 20-23}$ Fadd $^{-/-}$ & $\begin{array}{l}\text { Perinatal lethal } \\
\text { Proinflammatory } \\
\text { cytokine production }\end{array}$ & & & 69 \\
\hline
\end{tabular}




\begin{tabular}{|c|c|c|c|c|}
\hline Ripk1 $1^{\Delta R H I M}$ & $\begin{array}{l}\text { Perinatally lethal } \\
\text { Multiorgan cell death } \\
\text { and inflammation }\end{array}$ & & 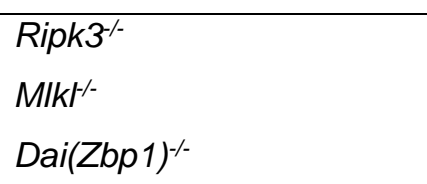 & 37 \\
\hline$I k k a^{-/}$ & $\begin{array}{l}\text { Perinatal death } \\
\text { Abnormal skin and } \\
\text { limb development }\end{array}$ & & & 95,96 \\
\hline $1 k k \beta^{-/-}$ & $\begin{array}{l}\text { Embr. lethal E14.5 } \\
\text { Liver apoptosis }\end{array}$ & & & 97,98 \\
\hline $\mathrm{NemO}^{-/-}$ & $\begin{array}{l}\text { Embr. lethal E14.5 } \\
\text { Liver apoptosis }\end{array}$ & & & 99 \\
\hline Tbk1 ${ }^{--}$ & Embr. lethal E14.5 & Ripk3 $^{-1}(\mathrm{nd})$ & Ripk1D138N & 42,100 \\
\hline CIAP1/2-- & $\begin{array}{l}\text { Embr. lethal E10.5 } \\
\text { Excessive cell death }\end{array}$ & 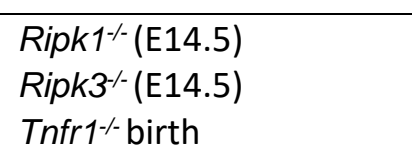 & & 101 \\
\hline Hoip $^{-/-}$ & $\begin{array}{l}\text { Embr. lethal E10.5 } \\
\text { Excessive cell death }\end{array}$ & $\begin{array}{l}\text { Tnf }^{/-} \text {(E15.5): Excessive } \\
\text { cell death } \\
\text { Tnfr1 }{ }^{-/}(\mathrm{E} 17.5): \text { ND } \\
\text { Ripk1 }^{K 45 A:} \text { Excessive cell } \\
\text { death }\end{array}$ & 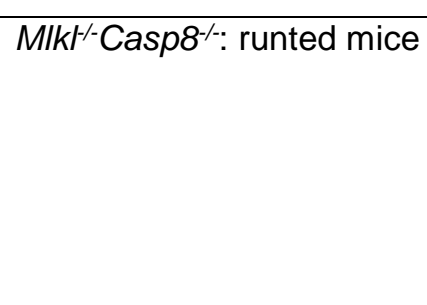 & 83,102 \\
\hline Hoil-1/- & $\begin{array}{l}\text { Embr. lethal E10.5 } \\
\text { Excessive cell death }\end{array}$ & 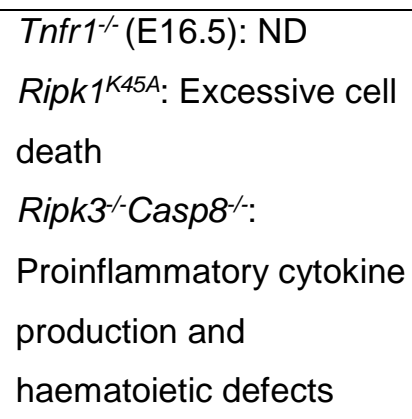 & 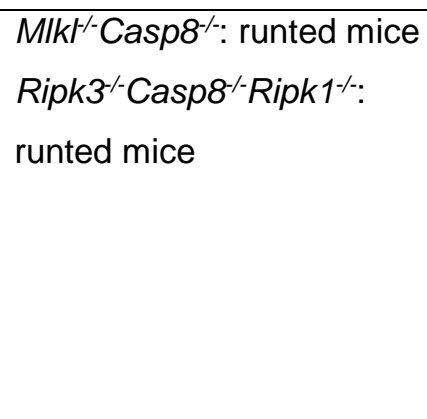 & 83 \\
\hline Cyld ${ }^{-/-}$ & $\begin{array}{l}\Delta \text { exon } 4 \text { : viable and } \\
\text { fertile } \\
\Delta \text { exons } 1 \text { and } 2 \text { : } \\
\text { viable, sterile males }\end{array}$ & & & 103,104 \\
\hline Tnfaip3 $3^{-/}\left(\mathrm{A} 20^{-/-}\right)$ & $\begin{array}{l}\text { Multi-organ } \\
\text { inflammation and } \\
\text { premature death }\end{array}$ & 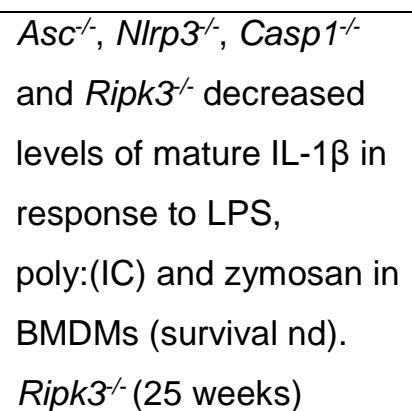 & MyD88 & $72,81,105,106$ \\
\hline
\end{tabular}




\begin{tabular}{|c|c|c|c|c|}
\hline & & 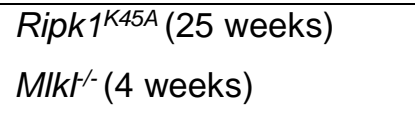 & & \\
\hline Otulingumby & $\begin{array}{l}\text { Embr. lethal E10.5 } \\
\text { Vascular defects, } \\
\text { Aberrant Wnt } \\
\text { signaling }\end{array}$ & & & 86 \\
\hline Otulin C129A & $\begin{array}{l}\text { Embr. lethal E10.5 } \\
\text { Excessive cell death }\end{array}$ & 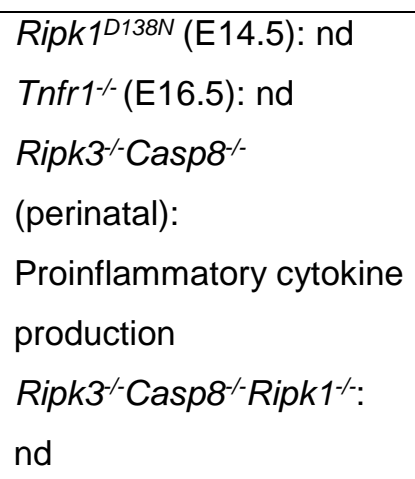 & $\begin{array}{l}\text { Ripk3 }{ }^{-/-} \text {Casp8 }^{-/-} \text {Ripk1 }^{+/-} \\
\text {Survived up to } 3 \text { months }\end{array}$ & 25 \\
\hline
\end{tabular}

Embr: embryonic; $\Delta$ : deletion/truncation; nd: non-determined 


\section{Conflict of interest}

The authors declare no conflict of interest.

\section{Acknowledgments}

This work was funded by a Wellcome Trust Senior Investigator Award (096831/Z/11/Z), an ERC Advanced grant (294880) and a Cancer Research UK programme grant (A17341) awarded to H.W. A postdoctoral fellowship was awarded to N.P. by the Swiss National Science Foundation (P300P3_158509) until April 2015.

\section{Reference list}

1. Kumar, H., Kawai, T. \& Akira, S. Pathogen recognition by the innate immune system. International reviews of immunology 30, 16-34 (2011).

2. Ofengeim, D. \& Yuan, J. Regulation of RIP1 kinase signalling at the crossroads of inflammation and cell death. Nature reviews. Molecular cell biology 14, 727-736 (2013).

3. Van Herreweghe, F., Festjens, N., Declercq, W. \& Vandenabeele, P. Tumor necrosis factormediated cell death: to break or to burst, that's the question. Cellular and molecular life sciences : CMLS 67, 1567-1579 (2010).

4. Dondelinger, Y., Darding, M., Bertrand, M.J. \& Walczak, H. Poly-ubiquitination in TNFR1mediated necroptosis. Cellular and molecular life sciences: CMLS 73, 2165-2176 (2016).

5. Haas, T.L. et al. Recruitment of the linear ubiquitin chain assembly complex stabilizes the TNFR1 signaling complex and is required for TNF-mediated gene induction. Molecular cell 36, 831844 (2009).

6. Gerlach, B. et al. Linear ubiquitination prevents inflammation and regulates immune signalling. Nature 471, 591-596 (2011).

7. Kirisako, T. et al. A ubiquitin ligase complex assembles linear polyubiquitin chains. The EMBO journal 25, 4877-4887 (2006).

8. Lafont, E. et al. TBK1 and IKKepsilon prevent TNF-induced cell death by RIPK1 phosphorylation. Nature cell biology (2018).

9. Micheau, O. \& Tschopp, J. Induction of TNF receptor I-mediated apoptosis via two sequential signaling complexes. Cell 114, 181-190 (2003).

10. Feoktistova, M., Geserick, P. \& Leverkus, M. Ripoptosome Analysis by Caspase-8 Coimmunoprecipitation. Cold Spring Harbor protocols 2016, pdb prot087403 (2016).

11. Cho, Y.S. et al. Phosphorylation-driven assembly of the RIP1-RIP3 complex regulates programmed necrosis and virus-induced inflammation. Cell 137, 1112-1123 (2009).

12. He, S. et al. Receptor interacting protein kinase-3 determines cellular necrotic response to TNF-alpha. Cell 137, 1100-1111 (2009).

13. Zhang, D.W. et al. RIP3, an energy metabolism regulator that switches TNF-induced cell death from apoptosis to necrosis. Science 325, 332-336 (2009).

14. Feoktistova, M. et al. cIAPs block Ripoptosome formation, a RIP1/caspase-8 containing intracellular cell death complex differentially regulated by cFLIP isoforms. Molecular cell 43, 449-463 (2011).

15. Lin, Y., Devin, A., Rodriguez, Y. \& Liu, Z.G. Cleavage of the death domain kinase RIP by caspase8 prompts TNF-induced apoptosis. Genes \& development 13, 2514-2526 (1999).

16. Feng, S. et al. Cleavage of RIP3 inactivates its caspase-independent apoptosis pathway by removal of kinase domain. Cellular signalling 19, 2056-2067 (2007).

17. Komander, D., Clague, M.J. \& Urbe, S. Breaking the chains: structure and function of the deubiquitinases. Nature reviews. Molecular cell biology 10, 550-563 (2009). 
18. Kupka, S., Reichert, M., Draber, P. \& Walczak, H. Formation and removal of poly-ubiquitin chains in the regulation of tumor necrosis factor-induced gene activation and cell death. The FEBS journal 283, 2626-2639 (2016).

19. Kovalenko, A. et al. The tumour suppressor CYLD negatively regulates NF-kappaB signalling by deubiquitination. Nature 424, 801-805 (2003).

20. Brummelkamp, T.R., Nijman, S.M., Dirac, A.M. \& Bernards, R. Loss of the cylindromatosis tumour suppressor inhibits apoptosis by activating NF-kappaB. Nature 424, 797-801 (2003).

21. Draber, P. et al. LUBAC-Recruited CYLD and A20 Regulate Gene Activation and Cell Death by Exerting Opposing Effects on Linear Ubiquitin in Signaling Complexes. Cell reports 13, 22582272 (2015).

22. Kupka, S. et al. SPATA2-Mediated Binding of CYLD to HOIP Enables CYLD Recruitment to Signaling Complexes. Cell reports 16, 2271-2280 (2016).

23. O'Donnell, M.A. et al. Caspase 8 inhibits programmed necrosis by processing CYLD. Nature cell biology 13, 1437-1442 (2011).

24. Damgaard, R.B. et al. The Deubiquitinase OTULIN Is an Essential Negative Regulator of Inflammation and Autoimmunity. Cell 166, 1215-1230 e1220 (2016).

25. Heger, K. et al. OTULIN limits cell death and inflammation by deubiquitinating LUBAC. Nature 559, 120-124 (2018).

26. Kolb, J.P., Oguin, T.H., 3rd, Oberst, A. \& Martinez, J. Programmed Cell Death and Inflammation: Winter Is Coming. Trends in immunology 38, 705-718 (2017).

27. Broz, P. \& Dixit, V.M. Inflammasomes: mechanism of assembly, regulation and signalling. Nature reviews. Immunology 16, 407-420 (2016).

28. Orning, P. et al. Pathogen blockade of TAK1 triggers caspase-8-dependent cleavage of gasdermin D and cell death. Science 362, 1064-1069 (2018).

29. Sarhan, J. et al. Caspase-8 induces cleavage of gasdermin D to elicit pyroptosis during Yersinia infection. Proceedings of the National Academy of Sciences of the United States of America 115, E10888-E10897 (2018).

30. Schneider, K.S. et al. The Inflammasome Drives GSDMD-Independent Secondary Pyroptosis and IL-1 Release in the Absence of Caspase-1 Protease Activity. Cell reports 21, 3846-3859 (2017).

31. Rickard, J.A. et al. RIPK1 regulates RIPK3-MLKL-driven systemic inflammation and emergency hematopoiesis. Cell 157, 1175-1188 (2014).

32. Dillon, C.P. et al. RIPK1 blocks early postnatal lethality mediated by caspase-8 and RIPK3. Cell 157, 1189-1202 (2014).

33. Newton, K. et al. Activity of protein kinase RIPK3 determines whether cells die by necroptosis or apoptosis. Science 343, 1357-1360 (2014).

34. Polykratis, A. et al. Cutting edge: RIPK1 Kinase inactive mice are viable and protected from TNF-induced necroptosis in vivo. J Immunol 193, 1539-1543 (2014).

35. Peltzer, N., Darding, M. \& Walczak, H. Holding RIPK1 on the Ubiquitin Leash in TNFR1 Signaling. Trends in cell biology 26, 445-461 (2016).

36. Degterev, A. et al. Identification of RIP1 kinase as a specific cellular target of necrostatins. Nature chemical biology 4, 313-321 (2008).

37. Newton, K. et al. RIPK1 inhibits ZBP1-driven necroptosis during development. Nature 540, 129-133 (2016).

38. Weinlich, R. \& Green, D.R. The two faces of receptor interacting protein kinase-1. Molecular cell 56, 469-480 (2014).

39. Annibaldi, A. et al. Ubiquitin-Mediated Regulation of RIPK1 Kinase Activity Independent of IKK and MK2. Molecular cell 69, 566-580 e565 (2018).

40. Annibaldi, A. \& Meier, P. Checkpoints in TNF-Induced Cell Death: Implications in Inflammation and Cancer. Trends in molecular medicine 24, 49-65 (2018). 
41. Dondelinger, Y. et al. NF-kappaB-Independent Role of IKKalpha/IKKbeta in Preventing RIPK1 Kinase-Dependent Apoptotic and Necroptotic Cell Death during TNF Signaling. Molecular cell 60, 63-76 (2015).

42. Xu, D. et al. TBK1 Suppresses RIPK1-Driven Apoptosis and Inflammation during Development and in Aging. Cell 174, 1477-1491 e1419 (2018).

43. Jaco, I. et al. MK2 Phosphorylates RIPK1 to Prevent TNF-Induced Cell Death. Molecular cell 66, 698-710 e695 (2017).

44. Menon, M.B. et al. p38(MAPK)/MK2-dependent phosphorylation controls cytotoxic RIPK1 signalling in inflammation and infection. Nature cell biology 19, 1248-1259 (2017).

45. Dondelinger, Y. et al. MK2 phosphorylation of RIPK1 regulates TNF-mediated cell death. Nature cell biology 19, 1237-1247 (2017).

46. Feldmann, M. Translating Molecular Insights in Autoimmunity into Effective Therapy. Annual Review of Immunology 27, 1-27 (2009).

47. Mompean, M. et al. The Structure of the Necrosome RIPK1-RIPK3 Core, a Human HeteroAmyloid Signaling Complex. Cell 173, 1244-1253 e1210 (2018).

48. Mandal, P. et al. RIP3 induces apoptosis independent of pronecrotic kinase activity. Molecular cell 56, 481-495 (2014).

49. Wu, J. et al. Mlkl knockout mice demonstrate the indispensable role of Mlkl in necroptosis. Cell research 23, 994-1006 (2013).

50. Wu, X.N. et al. Distinct roles of RIP1-RIP3 hetero- and RIP3-RIP3 homo-interaction in mediating necroptosis. Cell death and differentiation 21, 1709-1720 (2014).

51. Upton, J.W., Kaiser, W.J. \& Mocarski, E.S. Virus inhibition of RIP3-dependent necrosis. Cell host \& microbe 7, 302-313 (2010).

52. Kaiser, W.J. et al. Toll-like receptor 3-mediated necrosis via TRIF, RIP3, and MLKL. The Journal of biological chemistry 288, 31268-31279 (2013).

53. Lin, J. et al. RIPK1 counteracts ZBP1-mediated necroptosis to inhibit inflammation. Nature 540, 124-128 (2016).

54. Maelfait, J. et al. Sensing of viral and endogenous RNA by ZBP1/DAl induces necroptosis. The EMBO journal 36, 2529-2543 (2017).

55. Thapa, R.J. et al. DAI Senses Influenza A Virus Genomic RNA and Activates RIPK3-Dependent Cell Death. Cell host \& microbe 20, 674-681 (2016).

56. Takaoka, A. et al. DAI (DLM-1/ZBP1) is a cytosolic DNA sensor and an activator of innate immune response. Nature 448, 501-505 (2007).

57. Sun, L. et al. Mixed lineage kinase domain-like protein mediates necrosis signaling downstream of RIP3 kinase. Cell 148, 213-227 (2012).

58. Wang, H. et al. Mixed lineage kinase domain-like protein MLKL causes necrotic membrane disruption upon phosphorylation by RIP3. Molecular cell 54, 133-146 (2014).

59. Murphy, J.M. et al. The pseudokinase MLKL mediates necroptosis via a molecular switch mechanism. Immunity 39, 443-453 (2013).

60. Cai, Z. et al. Plasma membrane translocation of trimerized MLKL protein is required for TNFinduced necroptosis. Nature cell biology 16, 55-65 (2014).

61. Dondelinger, Y. et al. MLKL compromises plasma membrane integrity by binding to phosphatidylinositol phosphates. Cell reports 7, 971-981 (2014).

62. Huang, D. et al. The MLKL Channel in Necroptosis Is an Octamer Formed by Tetramers in a Dyadic Process. Molecular and cellular biology 37 (2017).

63. Yoon, S., Bogdanov, K., Kovalenko, A. \& Wallach, D. Necroptosis is preceded by nuclear translocation of the signaling proteins that induce it. Cell death and differentiation 23, 253260 (2016).

64. Gong, Y.N. et al. ESCRT-III Acts Downstream of MLKL to Regulate Necroptotic Cell Death and Its Consequences. Cell 169, 286-300 e216 (2017). 
65. Gong, Y.N., Guy, C., Crawford, J.C. \& Green, D.R. Biological events and molecular signaling following MLKL activation during necroptosis. Cell Cycle 16, 1748-1760 (2017).

66. Nogusa, S. et al. RIPK3 Activates Parallel Pathways of MLKL-Driven Necroptosis and FADDMediated Apoptosis to Protect against Influenza A Virus. Cell host \& microbe 20, 13-24 (2016).

67. Raju, S. et al. Kinase domain dimerization drives RIPK3-dependent necroptosis. Science signaling 11 (2018).

68. Dondelinger, Y. et al. RIPK3 contributes to TNFR1-mediated RIPK1 kinase-dependent apoptosis in conditions of cIAP1/2 depletion or TAK1 kinase inhibition. Cell death and differentiation 20, 1381-1392 (2013).

69. Zhao, Q. et al. RIPK3 Mediates Necroptosis during Embryonic Development and Postnatal Inflammation in Fadd-Deficient Mice. Cell reports 19, 798-808 (2017).

70. Najjar, M. et al. RIPK1 and RIPK3 Kinases Promote Cell-Death-Independent Inflammation by Toll-like Receptor 4. Immunity 45, 46-59 (2016).

71. Saleh, D. et al. Kinase Activities of RIPK1 and RIPK3 Can Direct IFN-beta Synthesis Induced by Lipopolysaccharide. J Immunol 198, 4435-4447 (2017).

72. Newton, K. et al. RIPK3 deficiency or catalytically inactive RIPK1 provides greater benefit than MLKL deficiency in mouse models of inflammation and tissue injury. Cell death and differentiation 23, 1565-1576 (2016).

73. Peterson, L.W. et al. RIPK1-dependent apoptosis bypasses pathogen blockade of innate signaling to promote immune defense. The Journal of experimental medicine 214, 3171-3182 (2017).

74. Downey, J. et al. RIPK3 interacts with MAVS to regulate type I IFN-mediated immunity to Influenza A virus infection. PLoS pathogens 13, e1006326 (2017).

75. Wang, X. et al. RNA viruses promote activation of the NLRP3 inflammasome through a RIP1RIP3-DRP1 signaling pathway. Nature immunology 15, 1126-1133 (2014).

76. Nogusa, S., Slifker, M.J., Ingram, J.P., Thapa, R.J. \& Balachandran, S. RIPK3 Is Largely Dispensable for RIG-I-Like Receptor- and Type I Interferon-Driven Transcriptional Responses to Influenza A Virus in Murine Fibroblasts. PloS one 11, e0158774 (2016).

77. Daniels, B.P. et al. RIPK3 Restricts Viral Pathogenesis via Cell Death-Independent Neuroinflammation. Cell 169, 301-313 e311 (2017).

78. Moriwaki, K. \& Chan, F.K. Necroptosis-independent signaling by the RIP kinases in inflammation. Cellular and molecular life sciences : CMLS 73, 2325-2334 (2016).

79. Vince, J.E. et al. Inhibitor of apoptosis proteins limit RIP3 kinase-dependent interleukin-1 activation. Immunity 36, 215-227 (2012).

80. Lawlor, K.E. et al. RIPK3 promotes cell death and NLRP3 inflammasome activation in the absence of MLKL. Nature communications 6, 6282 (2015).

81. Duong, B.H. et al. A20 restricts ubiquitination of pro-interleukin-1beta protein complexes and suppresses NLRP3 inflammasome activity. Immunity 42, 55-67 (2015).

82. Roderick, J.E. et al. Hematopoietic RIPK1 deficiency results in bone marrow failure caused by apoptosis and RIPK3-mediated necroptosis. Proceedings of the National Academy of Sciences of the United States of America 111, 14436-14441 (2014).

83. Peltzer, N. et al. LUBAC is essential for embryogenesis by preventing cell death and enabling haematopoiesis. Nature 557, 112-117 (2018).

84. Annibaldi, A. \& Meier, P. Ripk1 and haematopoiesis: a case for LUBAC and Ripk3. Cell death and differentiation 25, 1361-1363 (2018).

85. Kang, T.B., Jeong, J.S., Yang, S.H., Kovalenko, A. \& Wallach, D. Caspase-8 deficiency in mouse embryos triggers chronic RIPK1-dependent activation of inflammatory genes, independently of RIPK3. Cell death and differentiation 25, 1107-1117 (2018).

86. Rivkin, E. et al. The linear ubiquitin-specific deubiquitinase gumby regulates angiogenesis. Nature 498, 318-324 (2013). 
87. Varfolomeev, E.E. et al. Targeted disruption of the mouse Caspase 8 gene ablates cell death induction by the TNF receptors, Fas/Apo1, and DR3 and is lethal prenatally. Immunity 9, 267276 (1998).

88. Dillon, C.P. et al. Survival function of the FADD-CASPASE-8-cFLIP(L) complex. Cell reports 1, 401-407 (2012).

89. Kaiser, W.J. et al. RIP3 mediates the embryonic lethality of caspase-8-deficient mice. Nature 471, 368-372 (2011).

90. Alvarez-Diaz, S. et al. The Pseudokinase MLKL and the Kinase RIPK3 Have Distinct Roles in Autoimmune Disease Caused by Loss of Death-Receptor-Induced Apoptosis. Immunity 45, 513-526 (2016).

91. Zhang, J., Cado, D., Chen, A., Kabra, N.H. \& Winoto, A. Fas-mediated apoptosis and activationinduced T-cell proliferation are defective in mice lacking FADD/Mort1. Nature 392, 296-300 (1998).

92. Cusson, N., Oikemus, S., Kilpatrick, E.D., Cunningham, L. \& Kelliher, M. The death domain kinase RIP protects thymocytes from tumor necrosis factor receptor type 2-induced cell death. The Journal of experimental medicine 196, 15-26 (2002).

93. Anderton, H. et al. RIPK1 prevents TRADD-driven, but TNFR1 independent, apoptosis during development. Cell death and differentiation (2018).

94. Berger, S.B. et al. Cutting Edge: RIP1 kinase activity is dispensable for normal development but is a key regulator of inflammation in SHARPIN-deficient mice. J Immunol 192, 5476-5480 (2014).

95. Takeda, K. et al. Limb and skin abnormalities in mice lacking IKKalpha. Science 284, 313-316 (1999).

96. Li, Q. et al. IKK1-deficient mice exhibit abnormal development of skin and skeleton. Genes \& development 13, 1322-1328 (1999).

97. Li, Q., Van Antwerp, D., Mercurio, F., Lee, K.F. \& Verma, I.M. Severe liver degeneration in mice lacking the IkappaB kinase 2 gene. Science 284, 321-325 (1999).

98. Tanaka, M. et al. Embryonic lethality, liver degeneration, and impaired NF-kappa B activation in IKK-beta-deficient mice. Immunity 10, 421-429 (1999).

99. Rudolph, D. et al. Severe liver degeneration and lack of NF-kappaB activation in NEMO/IKKgamma-deficient mice. Genes \& development 14, 854-862 (2000).

100. Bonnard, M. et al. Deficiency of T2K leads to apoptotic liver degeneration and impaired NFkappaB-dependent gene transcription. The EMBO journal 19, 4976-4985 (2000).

101. Moulin, M. et al. IAPs limit activation of RIP kinases by TNF receptor 1 during development. The EMBO journal 31, 1679-1691 (2012).

102. Peltzer, N. et al. HOIP deficiency causes embryonic lethality by aberrant TNFR1-mediated endothelial cell death. Cell reports 9, 153-165 (2014).

103. Reiley, W.W. et al. Regulation of T cell development by the deubiquitinating enzyme CYLD. Nature immunology 7, 411-417 (2006).

104. Massoumi, R., Chmielarska, K., Hennecke, K., Pfeifer, A. \& Fassler, R. Cyld inhibits tumor cell proliferation by blocking Bcl-3-dependent NF-kappaB signaling. Cell 125, 665-677 (2006).

105. Turer, E.E. et al. Homeostatic MyD88-dependent signals cause lethal inflamMation in the absence of A20. The Journal of experimental medicine 205, 451-464 (2008).

106. Lee, E.G. et al. Failure to regulate TNF-induced NF-kappaB and cell death responses in A20deficient mice. Science 289, 2350-2354 (2000).

1. Kumar, H., Kawai, T. \& Akira, S. Pathogen recognition by the innate immune system. International reviews of immunology 30, 16-34 (2011).

2. Ofengeim, D. \& Yuan, J. Regulation of RIP1 kinase signalling at the crossroads of inflammation and cell death. Nature reviews. Molecular cell biology 14, 727-736 (2013). 
3. Van Herreweghe, F., Festjens, N., Declercq, W. \& Vandenabeele, P. Tumor necrosis factormediated cell death: to break or to burst, that's the question. Cellular and molecular life sciences : CMLS 67, 1567-1579 (2010).

4. Dondelinger, Y., Darding, M., Bertrand, M.J. \& Walczak, H. Poly-ubiquitination in TNFR1mediated necroptosis. Cellular and molecular life sciences : CMLS 73, 2165-2176 (2016).

5. Haas, T.L. et al. Recruitment of the linear ubiquitin chain assembly complex stabilizes the TNFR1 signaling complex and is required for TNF-mediated gene induction. Molecular cell 36, 831844 (2009).

6. Kirisako, T. et al. A ubiquitin ligase complex assembles linear polyubiquitin chains. The EMBO journal 25, 4877-4887 (2006).

7. Lafont, E. et al. TBK1 and IKKepsilon prevent TNF-induced cell death by RIPK1 phosphorylation. Nature cell biology (2018).

8. Micheau, O. \& Tschopp, J. Induction of TNF receptor I-mediated apoptosis via two sequential signaling complexes. Cell 114, 181-190 (2003).

9. Feoktistova, M., Geserick, P. \& Leverkus, M. Ripoptosome Analysis by Caspase-8 Coimmunoprecipitation. Cold Spring Harbor protocols 2016, pdb prot087403 (2016).

10. Cho, Y.S. et al. Phosphorylation-driven assembly of the RIP1-RIP3 complex regulates programmed necrosis and virus-induced inflammation. Cell 137, 1112-1123 (2009).

11. He, S. et al. Receptor interacting protein kinase-3 determines cellular necrotic response to TNF-alpha. Cell 137, 1100-1111 (2009).

12. Zhang, D.W. et al. RIP3, an energy metabolism regulator that switches TNF-induced cell death from apoptosis to necrosis. Science 325, 332-336 (2009).

13. Feoktistova, M. et al. clAPs block Ripoptosome formation, a RIP1/caspase-8 containing intracellular cell death complex differentially regulated by cFLIP isoforms. Molecular cell 43, 449-463 (2011).

14. Lin, Y., Devin, A., Rodriguez, Y. \& Liu, Z.G. Cleavage of the death domain kinase RIP by caspase8 prompts TNF-induced apoptosis. Genes \& development 13, 2514-2526 (1999).

15. Feng, S. et al. Cleavage of RIP3 inactivates its caspase-independent apoptosis pathway by removal of kinase domain. Cellular signalling 19, 2056-2067 (2007).

16. Komander, D., Clague, M.J. \& Urbe, S. Breaking the chains: structure and function of the deubiquitinases. Nature reviews. Molecular cell biology 10, 550-563 (2009).

17. Kupka, S., Reichert, M., Draber, P. \& Walczak, H. Formation and removal of poly-ubiquitin chains in the regulation of tumor necrosis factor-induced gene activation and cell death. The FEBS journal 283, 2626-2639 (2016).

18. Kovalenko, A. et al. The tumour suppressor CYLD negatively regulates NF-kappaB signalling by deubiquitination. Nature 424, 801-805 (2003).

19. Brummelkamp, T.R., Nijman, S.M., Dirac, A.M. \& Bernards, R. Loss of the cylindromatosis tumour suppressor inhibits apoptosis by activating NF-kappaB. Nature 424, 797-801 (2003).

20. Draber, P. et al. LUBAC-Recruited CYLD and A20 Regulate Gene Activation and Cell Death by Exerting Opposing Effects on Linear Ubiquitin in Signaling Complexes. Cell reports 13, 22582272 (2015).

21. Kupka, S. et al. SPATA2-Mediated Binding of CYLD to HOIP Enables CYLD Recruitment to Signaling Complexes. Cell reports 16, 2271-2280 (2016).

22. O'Donnell, M.A. et al. Caspase 8 inhibits programmed necrosis by processing CYLD. Nature cell biology 13, 1437-1442 (2011).

23. Damgaard, R.B. et al. The Deubiquitinase OTULIN Is an Essential Negative Regulator of Inflammation and Autoimmunity. Cell 166, 1215-1230 e1220 (2016).

24. Heger, K. et al. OTULIN limits cell death and inflammation by deubiquitinating LUBAC. Nature 559, 120-124 (2018).

25. Kolb, J.P., Oguin, T.H., 3rd, Oberst, A. \& Martinez, J. Programmed Cell Death and Inflammation: Winter Is Coming. Trends in immunology 38, 705-718 (2017). 
26. Broz, P. \& Dixit, V.M. Inflammasomes: mechanism of assembly, regulation and signalling. Nature reviews. Immunology 16, 407-420 (2016).

27. Orning, P. et al. Pathogen blockade of TAK1 triggers caspase-8-dependent cleavage of gasdermin D and cell death. Science 362, 1064-1069 (2018).

28. Sarhan, J. et al. Caspase- 8 induces cleavage of gasdermin D to elicit pyroptosis during Yersinia infection. Proceedings of the National Academy of Sciences of the United States of America 115, E10888-E10897 (2018).

29. Schneider, K.S. et al. The Inflammasome Drives GSDMD-Independent Secondary Pyroptosis and IL-1 Release in the Absence of Caspase-1 Protease Activity. Cell reports 21, 3846-3859 (2017).

30. Rickard, J.A. et al. RIPK1 regulates RIPK3-MLKL-driven systemic inflammation and emergency hematopoiesis. Cell 157, 1175-1188 (2014).

31. Dillon, C.P. et al. RIPK1 blocks early postnatal lethality mediated by caspase-8 and RIPK3. Cell 157, 1189-1202 (2014).

32. Newton, K. et al. Activity of protein kinase RIPK3 determines whether cells die by necroptosis or apoptosis. Science 343, 1357-1360 (2014).

33. Polykratis, A. et al. Cutting edge: RIPK1 Kinase inactive mice are viable and protected from TNF-induced necroptosis in vivo. J Immunol 193, 1539-1543 (2014).

34. Peltzer, N., Darding, M. \& Walczak, H. Holding RIPK1 on the Ubiquitin Leash in TNFR1 Signaling. Trends in cell biology 26, 445-461 (2016).

35. Degterev, A. et al. Identification of RIP1 kinase as a specific cellular target of necrostatins. Nature chemical biology 4, 313-321 (2008).

36. Newton, K. et al. RIPK1 inhibits ZBP1-driven necroptosis during development. Nature 540, 129-133 (2016).

37. Weinlich, R. \& Green, D.R. The two faces of receptor interacting protein kinase-1. Molecular cell 56, 469-480 (2014).

38. Annibaldi, A. et al. Ubiquitin-Mediated Regulation of RIPK1 Kinase Activity Independent of IKK and MK2. Molecular cell 69, 566-580 e565 (2018).

39. Annibaldi, A. \& Meier, P. Checkpoints in TNF-Induced Cell Death: Implications in Inflammation and Cancer. Trends in molecular medicine 24, 49-65 (2018).

40. Dondelinger, Y. et al. NF-kappaB-Independent Role of IKKalpha/IKKbeta in Preventing RIPK1 Kinase-Dependent Apoptotic and Necroptotic Cell Death during TNF Signaling. Molecular cell 60, 63-76 (2015).

41. Xu, D. et al. TBK1 Suppresses RIPK1-Driven Apoptosis and Inflammation during Development and in Aging. Cell 174, 1477-1491 e1419 (2018).

42. Jaco, I. et al. MK2 Phosphorylates RIPK1 to Prevent TNF-Induced Cell Death. Molecular cell 66, 698-710 e695 (2017).

43. Menon, M.B. et al. p38(MAPK)/MK2-dependent phosphorylation controls cytotoxic RIPK1 signalling in inflammation and infection. Nature cell biology 19, 1248-1259 (2017).

44. Dondelinger, Y. et al. MK2 phosphorylation of RIPK1 regulates TNF-mediated cell death. Nature cell biology 19, 1237-1247 (2017).

45. Feldmann, M. Translating Molecular Insights in Autoimmunity into Effective Therapy. Annual Review of Immunology 27, 1-27 (2009).

46. Mompean, M. et al. The Structure of the Necrosome RIPK1-RIPK3 Core, a Human HeteroAmyloid Signaling Complex. Cell 173, 1244-1253 e1210 (2018).

47. Mandal, P. et al. RIP3 induces apoptosis independent of pronecrotic kinase activity. Molecular cell 56, 481-495 (2014).

48. Wu, J. et al. Mlkl knockout mice demonstrate the indispensable role of Mlkl in necroptosis. Cell research 23, 994-1006 (2013).

49. Wu, X.N. et al. Distinct roles of RIP1-RIP3 hetero- and RIP3-RIP3 homo-interaction in mediating necroptosis. Cell death and differentiation 21, 1709-1720 (2014). 
50. Upton, J.W., Kaiser, W.J. \& Mocarski, E.S. Virus inhibition of RIP3-dependent necrosis. Cell host \& microbe 7, 302-313 (2010).

51. Kaiser, W.J. et al. Toll-like receptor 3-mediated necrosis via TRIF, RIP3, and MLKL. The Journal of biological chemistry 288, 31268-31279 (2013).

52. Lin, J. et al. RIPK1 counteracts ZBP1-mediated necroptosis to inhibit inflammation. Nature 540, 124-128 (2016).

53. Maelfait, J. et al. Sensing of viral and endogenous RNA by ZBP1/DAl induces necroptosis. The EMBO journal 36, 2529-2543 (2017).

54. Thapa, R.J. et al. DAI Senses Influenza A Virus Genomic RNA and Activates RIPK3-Dependent Cell Death. Cell host \& microbe 20, 674-681 (2016).

55. Takaoka, A. et al. DAI (DLM-1/ZBP1) is a cytosolic DNA sensor and an activator of innate immune response. Nature 448, 501-505 (2007).

56. Sun, L. et al. Mixed lineage kinase domain-like protein mediates necrosis signaling downstream of RIP3 kinase. Cell 148, 213-227 (2012).

57. Wang, H. et al. Mixed lineage kinase domain-like protein MLKL causes necrotic membrane disruption upon phosphorylation by RIP3. Molecular cell 54, 133-146 (2014).

58. Murphy, J.M. et al. The pseudokinase MLKL mediates necroptosis via a molecular switch mechanism. Immunity 39, 443-453 (2013).

59. Cai, Z. et al. Plasma membrane translocation of trimerized MLKL protein is required for TNFinduced necroptosis. Nature cell biology 16, 55-65 (2014).

60. Dondelinger, Y. et al. MLKL compromises plasma membrane integrity by binding to phosphatidylinositol phosphates. Cell reports 7, 971-981 (2014).

61. Huang, D. et al. The MLKL Channel in Necroptosis Is an Octamer Formed by Tetramers in a Dyadic Process. Molecular and cellular biology 37 (2017).

62. Yoon, S., Bogdanov, K., Kovalenko, A. \& Wallach, D. Necroptosis is preceded by nuclear translocation of the signaling proteins that induce it. Cell death and differentiation 23, 253260 (2016).

63. Gong, Y.N. et al. ESCRT-III Acts Downstream of MLKL to Regulate Necroptotic Cell Death and Its Consequences. Cell 169, 286-300 e216 (2017).

64. Gong, Y.N., Guy, C., Crawford, J.C. \& Green, D.R. Biological events and molecular signaling following MLKL activation during necroptosis. Cell Cycle 16, 1748-1760 (2017).

65. Nogusa, S. et al. RIPK3 Activates Parallel Pathways of MLKL-Driven Necroptosis and FADDMediated Apoptosis to Protect against Influenza A Virus. Cell host \& microbe 20, 13-24 (2016).

66. Raju, S. et al. Kinase domain dimerization drives RIPK3-dependent necroptosis. Science signaling 11 (2018).

67. Dondelinger, Y. et al. RIPK3 contributes to TNFR1-mediated RIPK1 kinase-dependent apoptosis in conditions of cIAP1/2 depletion or TAK1 kinase inhibition. Cell death and differentiation 20, 1381-1392 (2013).

68. Zhao, Q. et al. RIPK3 Mediates Necroptosis during Embryonic Development and Postnatal Inflammation in Fadd-Deficient Mice. Cell reports 19, 798-808 (2017).

69. Najjar, M. et al. RIPK1 and RIPK3 Kinases Promote Cell-Death-Independent Inflammation by Toll-like Receptor 4. Immunity 45, 46-59 (2016).

70. Saleh, D. et al. Kinase Activities of RIPK1 and RIPK3 Can Direct IFN-beta Synthesis Induced by Lipopolysaccharide. J Immunol 198, 4435-4447 (2017).

71. Newton, K. et al. RIPK3 deficiency or catalytically inactive RIPK1 provides greater benefit than MLKL deficiency in mouse models of inflammation and tissue injury. Cell death and differentiation 23, 1565-1576 (2016).

72. Peterson, L.W. et al. RIPK1-dependent apoptosis bypasses pathogen blockade of innate signaling to promote immune defense. The Journal of experimental medicine 214, 3171-3182 (2017). 
73. Downey, J. et al. RIPK3 interacts with MAVS to regulate type I IFN-mediated immunity to Influenza A virus infection. PLoS pathogens 13, e1006326 (2017).

74. Wang, X. et al. RNA viruses promote activation of the NLRP3 inflammasome through a RIP1RIP3-DRP1 signaling pathway. Nature immunology 15, 1126-1133 (2014).

75. Nogusa, S., Slifker, M.J., Ingram, J.P., Thapa, R.J. \& Balachandran, S. RIPK3 Is Largely Dispensable for RIG-I-Like Receptor- and Type I Interferon-Driven Transcriptional Responses to Influenza A Virus in Murine Fibroblasts. PloS one 11, e0158774 (2016).

76. Daniels, B.P. et al. RIPK3 Restricts Viral Pathogenesis via Cell Death-Independent Neuroinflammation. Cell 169, 301-313 e311 (2017).

77. Moriwaki, K. \& Chan, F.K. Necroptosis-independent signaling by the RIP kinases in inflammation. Cellular and molecular life sciences : CMLS 73, 2325-2334 (2016).

78. Vince, J.E. et al. Inhibitor of apoptosis proteins limit RIP3 kinase-dependent interleukin-1 activation. Immunity 36, 215-227 (2012).

79. Lawlor, K.E. et al. RIPK3 promotes cell death and NLRP3 inflammasome activation in the absence of MLKL. Nature communications 6, 6282 (2015).

80. Duong, B.H. et al. A20 restricts ubiquitination of pro-interleukin-1beta protein complexes and suppresses NLRP3 inflammasome activity. Immunity 42, 55-67 (2015).

81. Roderick, J.E. et al. Hematopoietic RIPK1 deficiency results in bone marrow failure caused by apoptosis and RIPK3-mediated necroptosis. Proceedings of the National Academy of Sciences of the United States of America 111, 14436-14441 (2014).

82. Peltzer, N. et al. LUBAC is essential for embryogenesis by preventing cell death and enabling haematopoiesis. Nature 557, 112-117 (2018).

83. Annibaldi, A. \& Meier, P. Ripk1 and haematopoiesis: a case for LUBAC and Ripk3. Cell death and differentiation 25, 1361-1363 (2018).

84. Kang, T.B., Jeong, J.S., Yang, S.H., Kovalenko, A. \& Wallach, D. Caspase-8 deficiency in mouse embryos triggers chronic RIPK1-dependent activation of inflammatory genes, independently of RIPK3. Cell death and differentiation 25, 1107-1117 (2018).

85. Rivkin, E. et al. The linear ubiquitin-specific deubiquitinase gumby regulates angiogenesis. Nature 498, 318-324 (2013).

86. Varfolomeev, E.E. et al. Targeted disruption of the mouse Caspase 8 gene ablates cell death induction by the TNF receptors, Fas/Apo1, and DR3 and is lethal prenatally. Immunity 9, 267276 (1998).

87. Dillon, C.P. et al. Survival function of the FADD-CASPASE-8-cFLIP(L) complex. Cell reports 1, 401-407 (2012).

88. Kaiser, W.J. et al. RIP3 mediates the embryonic lethality of caspase-8-deficient mice. Nature 471, 368-372 (2011).

89. Alvarez-Diaz, S. et al. The Pseudokinase MLKL and the Kinase RIPK3 Have Distinct Roles in Autoimmune Disease Caused by Loss of Death-Receptor-Induced Apoptosis. Immunity 45, 513-526 (2016).

90. Zhang, J., Cado, D., Chen, A., Kabra, N.H. \& Winoto, A. Fas-mediated apoptosis and activationinduced T-cell proliferation are defective in mice lacking FADD/Mort1. Nature 392, 296-300 (1998).

91. Cusson, N., Oikemus, S., Kilpatrick, E.D., Cunningham, L. \& Kelliher, M. The death domain kinase RIP protects thymocytes from tumor necrosis factor receptor type 2-induced cell death. The Journal of experimental medicine 196, 15-26 (2002).

92. Anderton, H. et al. RIPK1 prevents TRADD-driven, but TNFR1 independent, apoptosis during development. Cell death and differentiation (2018).

93. Berger, S.B. et al. Cutting Edge: RIP1 kinase activity is dispensable for normal development but is a key regulator of inflammation in SHARPIN-deficient mice. J Immunol 192, 5476-5480 (2014). 
94. Takeda, K. et al. Limb and skin abnormalities in mice lacking IKKalpha. Science 284, 313-316 (1999).

95. Li, Q. et al. IKK1-deficient mice exhibit abnormal development of skin and skeleton. Genes \& development 13, 1322-1328 (1999).

96. Li, Q., Van Antwerp, D., Mercurio, F., Lee, K.F. \& Verma, I.M. Severe liver degeneration in mice lacking the IkappaB kinase 2 gene. Science 284, 321-325 (1999).

97. Tanaka, M. et al. Embryonic lethality, liver degeneration, and impaired NF-kappa B activation in IKK-beta-deficient mice. Immunity 10, 421-429 (1999).

98. Rudolph, D. et al. Severe liver degeneration and lack of NF-kappaB activation in NEMO/IKKgamma-deficient mice. Genes \& development 14, 854-862 (2000).

99. Bonnard, M. et al. Deficiency of T2K leads to apoptotic liver degeneration and impaired NFkappaB-dependent gene transcription. The EMBO journal 19, 4976-4985 (2000).

100. Moulin, M. et al. IAPs limit activation of RIP kinases by TNF receptor 1 during development. The EMBO journal 31, 1679-1691 (2012).

101. Peltzer, N. et al. HOIP deficiency causes embryonic lethality by aberrant TNFR1-mediated endothelial cell death. Cell reports 9, 153-165 (2014).

102. Reiley, W.W. et al. Regulation of T cell development by the deubiquitinating enzyme CYLD. Nature immunology 7, 411-417 (2006).

103. Massoumi, R., Chmielarska, K., Hennecke, K., Pfeifer, A. \& Fassler, R. Cyld inhibits tumor cell proliferation by blocking Bcl-3-dependent NF-kappaB signaling. Cell 125, 665-677 (2006).

104. Turer, E.E. et al. Homeostatic MyD88-dependent signals cause lethal inflamMation in the absence of A20. The Journal of experimental medicine 205, 451-464 (2008).

105. Lee, E.G. et al. Failure to regulate TNF-induced NF-kappaB and cell death responses in A20deficient mice. Science 289, 2350-2354 (2000).

1. Kumar, H., Kawai, T. \& Akira, S. Pathogen recognition by the innate immune system. International reviews of immunology 30, 16-34 (2011).

2. Ofengeim, D. \& Yuan, J. Regulation of RIP1 kinase signalling at the crossroads of inflammation and cell death. Nature reviews. Molecular cell biology 14, 727-736 (2013).

3. Van Herreweghe, F., Festjens, N., Declercq, W. \& Vandenabeele, P. Tumor necrosis factor-mediated cell death: to break or to burst, that's the question. Cellular and molecular life sciences: CMLS 67, 1567-1579 (2010).

4. Dondelinger, Y., Darding, M., Bertrand, M.J. \& Walczak, H. Poly-ubiquitination in TNFR1-mediated necroptosis. Cellular and molecular life sciences : CMLS 73, 21652176 (2016).

5. Haas, T.L. et al. Recruitment of the linear ubiquitin chain assembly complex stabilizes the TNF-R1 signaling complex and is required for TNF-mediated gene induction. Molecular cell 36, 831-844 (2009).

6. Gerlach, K. et al. Transcription factor NFATc2 controls the emergence of colon cancer associated with IL-6-dependent colitis. Cancer research 72, 4340-4350 (2012).

7. Kirisako, T. et al. A ubiquitin ligase complex assembles linear polyubiquitin chains. The EMBO journal 25, 4877-4887 (2006).

8. Lafont, E. et al. TBK1 and IKKepsilon prevent TNF-induced cell death by RIPK1 phosphorylation. Nature cell biology (2018).

9. Micheau, O. \& Tschopp, J. Induction of TNF receptor I-mediated apoptosis via two sequential signaling complexes. Cell 114, 181-190 (2003).

10. Feoktistova, M., Geserick, P. \& Leverkus, M. Ripoptosome Analysis by Caspase-8 Coimmunoprecipitation. Cold Spring Harbor protocols 2016, pdb prot087403 (2016).

11. Cho, Y.S. et al. Phosphorylation-driven assembly of the RIP1-RIP3 complex regulates programmed necrosis and virus-induced inflammation. Cell 137, 1112-1123 (2009). 
12. He, S. et al. Receptor interacting protein kinase-3 determines cellular necrotic response to TNF-alpha. Cell 137, 1100-1111 (2009).

13. Zhang, D.W. et al. RIP3, an energy metabolism regulator that switches TNF-induced cell death from apoptosis to necrosis. Science 325, 332-336 (2009).

14. Feoktistova, M. et al. clAPs block Ripoptosome formation, a RIP1/caspase-8 containing intracellular cell death complex differentially regulated by cFLIP isoforms. Molecular cell 43, 449-463 (2011).

15. Lin, Y., Devin, A., Rodriguez, Y. \& Liu, Z.G. Cleavage of the death domain kinase RIP by caspase-8 prompts TNF-induced apoptosis. Genes \& development 13, 2514-2526 (1999).

16. Feng, S. et al. Cleavage of RIP3 inactivates its caspase-independent apoptosis pathway by removal of kinase domain. Cellular signalling 19, 2056-2067 (2007).

17. Komander, D., Clague, M.J. \& Urbe, S. Breaking the chains: structure and function of the deubiquitinases. Nature reviews. Molecular cell biology 10, 550-563 (2009).

18. Kupka, S., Reichert, M., Draber, P. \& Walczak, H. Formation and removal of polyubiquitin chains in the regulation of tumor necrosis factor-induced gene activation and cell death. The FEBS journal 283, 2626-2639 (2016).

19. Kovalenko, A. et al. The tumour suppressor CYLD negatively regulates NF-kappaB signalling by deubiquitination. Nature 424, 801-805 (2003).

20. Brummelkamp, T.R., Nijman, S.M., Dirac, A.M. \& Bernards, R. Loss of the cylindromatosis tumour suppressor inhibits apoptosis by activating NF-kappaB. Nature 424, 797-801 (2003).

21. Draber, P. et al. LUBAC-Recruited CYLD and A20 Regulate Gene Activation and Cell Death by Exerting Opposing Effects on Linear Ubiquitin in Signaling Complexes. Cell reports 13, 2258-2272 (2015).

22. Kupka, S. et al. SPATA2-Mediated Binding of CYLD to HOIP Enables CYLD Recruitment to Signaling Complexes. Cell reports 16, 2271-2280 (2016).

23. O'Donnell, M.A. et al. Caspase 8 inhibits programmed necrosis by processing CYLD. Nature cell biology 13, 1437-1442 (2011).

24. Damgaard, R.B. et al. The Deubiquitinase OTULIN Is an Essential Negative Regulator of Inflammation and Autoimmunity. Cell 166, 1215-1230 e1220 (2016).

25. Heger, K. et al. OTULIN limits cell death and inflammation by deubiquitinating LUBAC. Nature 559, 120-124 (2018).

26. Kolb, J.P., Oguin, T.H., 3rd, Oberst, A. \& Martinez, J. Programmed Cell Death and Inflammation: Winter Is Coming. Trends in immunology 38, 705-718 (2017).

27. Broz, P. \& Dixit, V.M. Inflammasomes: mechanism of assembly, regulation and signalling. Nature reviews. Immunology 16, 407-420 (2016).

28. Orning, P. et al. Pathogen blockade of TAK1 triggers caspase-8-dependent cleavage of gasdermin D and cell death. Science 362, 1064-1069 (2018).

29. Sarhan, J. et al. Caspase-8 induces cleavage of gasdermin D to elicit pyroptosis during Yersinia infection. Proceedings of the National Academy of Sciences of the United States of America 115, E10888-E10897 (2018).

30. Schneider, K.S. et al. The Inflammasome Drives GSDMD-Independent Secondary Pyroptosis and IL-1 Release in the Absence of Caspase-1 Protease Activity. Cell reports 21, 3846-3859 (2017).

31. Rickard, J.A. et al. RIPK1 regulates RIPK3-MLKL-driven systemic inflammation and emergency hematopoiesis. Cell 157, 1175-1188 (2014).

32. Dillon, C.P. et al. RIPK1 blocks early postnatal lethality mediated by caspase-8 and RIPK3. Cell 157, 1189-1202 (2014).

33. Newton, K. et al. Activity of protein kinase RIPK3 determines whether cells die by necroptosis or apoptosis. Science 343, 1357-1360 (2014).

34. Polykratis, A. et al. Cutting edge: RIPK1 Kinase inactive mice are viable and protected from TNF-induced necroptosis in vivo. J Immunol 193, 1539-1543 (2014).

35. Peltzer, N., Darding, M. \& Walczak, H. Holding RIPK1 on the Ubiquitin Leash in TNFR1 Signaling. Trends in cell biology 26, 445-461 (2016). 
36. Degterev, A. et al. Identification of RIP1 kinase as a specific cellular target of necrostatins. Nature chemical biology 4, 313-321 (2008).

37. Newton, K. et al. RIPK1 inhibits ZBP1-driven necroptosis during development. Nature 540, 129-133 (2016).

38. Weinlich, R. \& Green, D.R. The two faces of receptor interacting protein kinase-1. Molecular cell 56, 469-480 (2014).

39. Annibaldi, A. et al. Ubiquitin-Mediated Regulation of RIPK1 Kinase Activity Independent of IKK and MK2. Molecular cell 69, 566-580 e565 (2018).

40. Annibaldi, A. \& Meier, P. Checkpoints in TNF-Induced Cell Death: Implications in Inflammation and Cancer. Trends in molecular medicine 24, 49-65 (2018).

41. Dondelinger, Y. et al. NF-kappaB-Independent Role of IKKalpha/IKKbeta in Preventing RIPK1 Kinase-Dependent Apoptotic and Necroptotic Cell Death during TNF Signaling. Molecular cell 60, 63-76 (2015).

42. Xu, D. et al. TBK1 Suppresses RIPK1-Driven Apoptosis and Inflammation during Development and in Aging. Cell 174, 1477-1491 e1419 (2018).

43. Jaco, I. et al. MK2 Phosphorylates RIPK1 to Prevent TNF-Induced Cell Death. Molecular cell 66, 698-710 e695 (2017).

44. Menon, M.B. et al. p38(MAPK)/MK2-dependent phosphorylation controls cytotoxic RIPK1 signalling in inflammation and infection. Nature cell biology 19, 1248-1259 (2017).

45. Dondelinger, Y. et al. MK2 phosphorylation of RIPK1 regulates TNF-mediated cell death. Nature cell biology 19, 1237-1247 (2017).

46. Feldmann, M. Translating Molecular Insights in Autoimmunity into Effective Therapy. Annual Review of Immunology 27, 1-27 (2009).

47. Mompean, M. et al. The Structure of the Necrosome RIPK1-RIPK3 Core, a Human Hetero-Amyloid Signaling Complex. Cell 173, 1244-1253 e1210 (2018).

48. Mandal, P. et al. RIP3 induces apoptosis independent of pronecrotic kinase activity. Molecular cell 56, 481-495 (2014).

49. Wu, J. et al. Mlkl knockout mice demonstrate the indispensable role of Mlkl in necroptosis. Cell research 23, 994-1006 (2013).

50. Wu, X.N. et al. Distinct roles of RIP1-RIP3 hetero- and RIP3-RIP3 homo-interaction in mediating necroptosis. Cell death and differentiation 21, 1709-1720 (2014).

51. Upton, J.W., Kaiser, W.J. \& Mocarski, E.S. Virus inhibition of RIP3-dependent necrosis. Cell host \& microbe 7, 302-313 (2010).

52. Kaiser, W.J. et al. Toll-like receptor 3-mediated necrosis via TRIF, RIP3, and MLKL. The Journal of biological chemistry 288, 31268-31279 (2013).

53. Lin, J. et al. RIPK1 counteracts ZBP1-mediated necroptosis to inhibit inflammation. Nature 540, 124-128 (2016).

54. Maelfait, J. et al. Sensing of viral and endogenous RNA by ZBP1/DAI induces necroptosis. The EMBO journal 36, 2529-2543 (2017).

55. Thapa, R.J. et al. DAI Senses Influenza A Virus Genomic RNA and Activates RIPK3Dependent Cell Death. Cell host \& microbe 20, 674-681 (2016).

56. Takaoka, A. et al. DAI (DLM-1/ZBP1) is a cytosolic DNA sensor and an activator of innate immune response. Nature 448, 501-505 (2007).

57. Sun, L. et al. Mixed lineage kinase domain-like protein mediates necrosis signaling downstream of RIP3 kinase. Cell 148, 213-227 (2012).

58. Wang, $H$. et al. Mixed lineage kinase domain-like protein MLKL causes necrotic membrane disruption upon phosphorylation by RIP3. Molecular cell 54, 133-146 (2014).

59. Murphy, J.M. et al. The pseudokinase MLKL mediates necroptosis via a molecular switch mechanism. Immunity 39, 443-453 (2013).

60. Cai, Z. et al. Plasma membrane translocation of trimerized MLKL protein is required for TNF-induced necroptosis. Nature cell biology 16, 55-65 (2014).

61. Dondelinger, Y. et al. MLKL compromises plasma membrane integrity by binding to phosphatidylinositol phosphates. Cell reports 7, 971-981 (2014). 
62. Huang, D. et al. The MLKL Channel in Necroptosis Is an Octamer Formed by Tetramers in a Dyadic Process. Molecular and cellular biology 37 (2017).

63. Yoon, S., Bogdanov, K., Kovalenko, A. \& Wallach, D. Necroptosis is preceded by nuclear translocation of the signaling proteins that induce it. Cell death and differentiation 23, 253-260 (2016).

64. Gong, Y.N. et al. ESCRT-III Acts Downstream of MLKL to Regulate Necroptotic Cell Death and Its Consequences. Cell 169, 286-300 e216 (2017).

65. Gong, Y.N., Guy, C., Crawford, J.C. \& Green, D.R. Biological events and molecular signaling following MLKL activation during necroptosis. Cell Cycle 16, 1748-1760 (2017).

66. Nogusa, S. et al. RIPK3 Activates Parallel Pathways of MLKL-Driven Necroptosis and FADD-Mediated Apoptosis to Protect against Influenza A Virus. Cell host \& microbe 20, 13-24 (2016).

67. Raju, S. et al. Kinase domain dimerization drives RIPK3-dependent necroptosis. Science signaling 11 (2018).

68. Dondelinger, Y. et al. RIPK3 contributes to TNFR1-mediated RIPK1 kinase-dependent apoptosis in conditions of cIAP1/2 depletion or TAK1 kinase inhibition. Cell death and differentiation 20, 1381-1392 (2013).

69. Zhao, Q. et al. RIPK3 Mediates Necroptosis during Embryonic Development and Postnatal Inflammation in Fadd-Deficient Mice. Cell reports 19, 798-808 (2017).

70. Najjar, M. et al. RIPK1 and RIPK3 Kinases Promote Cell-Death-Independent Inflammation by Toll-like Receptor 4. Immunity 45, 46-59 (2016).

71. Saleh, D. et al. Kinase Activities of RIPK1 and RIPK3 Can Direct IFN-beta Synthesis Induced by Lipopolysaccharide. J Immunol 198, 4435-4447 (2017).

72. Newton, K. et al. RIPK3 deficiency or catalytically inactive RIPK1 provides greater benefit than MLKL deficiency in mouse models of inflammation and tissue injury. Cell death and differentiation 23, 1565-1576 (2016).

73. Peterson, L.W. et al. RIPK1-dependent apoptosis bypasses pathogen blockade of innate signaling to promote immune defense. The Journal of experimental medicine 214, 3171-3182 (2017).

74. Downey, J. et al. RIPK3 interacts with MAVS to regulate type I IFN-mediated immunity to Influenza A virus infection. PLoS pathogens 13, e1006326 (2017).

75. Wang, $X$. et al. RNA viruses promote activation of the NLRP3 inflammasome through a RIP1-RIP3-DRP1 signaling pathway. Nature immunology 15, 1126-1133 (2014).

76. Nogusa, S., Slifker, M.J., Ingram, J.P., Thapa, R.J. \& Balachandran, S. RIPK3 Is Largely Dispensable for RIG-I-Like Receptor- and Type I Interferon-Driven Transcriptional Responses to Influenza A Virus in Murine Fibroblasts. PloS one 11, e0158774 (2016).

77. Daniels, B.P. et al. RIPK3 Restricts Viral Pathogenesis via Cell Death-Independent Neuroinflammation. Cell 169, 301-313 e311 (2017).

78. Moriwaki, K. \& Chan, F.K. Necroptosis-independent signaling by the RIP kinases in inflammation. Cellular and molecular life sciences: CMLS 73, 2325-2334 (2016).

79. Vince, J.E. et al. Inhibitor of apoptosis proteins limit RIP3 kinase-dependent interleukin-1 activation. Immunity 36, 215-227 (2012).

80. Lawlor, K.E. et al. RIPK3 promotes cell death and NLRP3 inflammasome activation in the absence of MLKL. Nature communications 6, 6282 (2015).

81. Duong, B.H. et al. A20 restricts ubiquitination of pro-interleukin-1beta protein complexes and suppresses NLRP3 inflammasome activity. Immunity 42, 55-67 (2015).

82. Roderick, J.E. et al. Hematopoietic RIPK1 deficiency results in bone marrow failure caused by apoptosis and RIPK3-mediated necroptosis. Proceedings of the National Academy of Sciences of the United States of America 111, 14436-14441 (2014).

83. Peltzer, N. et al. LUBAC is essential for embryogenesis by preventing cell death and enabling haematopoiesis. Nature 557, 112-117 (2018).

84. Annibaldi, A. \& Meier, P. Ripk1 and haematopoiesis: a case for LUBAC and Ripk3. Cell death and differentiation 25, 1361-1363 (2018). 
85. Kang, T.B., Jeong, J.S., Yang, S.H., Kovalenko, A. \& Wallach, D. Caspase-8 deficiency in mouse embryos triggers chronic RIPK1-dependent activation of inflammatory genes, independently of RIPK3. Cell death and differentiation 25, 1107-1117 (2018).

86. Rivkin, E. et al. The linear ubiquitin-specific deubiquitinase gumby regulates angiogenesis. Nature 498, 318-324 (2013).

87. Varfolomeev, E.E. et al. Targeted disruption of the mouse Caspase 8 gene ablates cell death induction by the TNF receptors, Fas/Apo1, and DR3 and is lethal prenatally. Immunity 9, 267-276 (1998).

88. Dillon, C.P. et al. Survival function of the FADD-CASPASE-8-cFLIP(L) complex. Cell reports 1, 401-407 (2012).

89. Kaiser, W.J. et al. RIP3 mediates the embryonic lethality of caspase-8-deficient mice. Nature 471, 368-372 (2011).

90. Alvarez-Diaz, S. et al. The Pseudokinase MLKL and the Kinase RIPK3 Have Distinct Roles in Autoimmune Disease Caused by Loss of Death-Receptor-Induced Apoptosis. Immunity 45, 513-526 (2016).

91. Zhang, J., Cado, D., Chen, A., Kabra, N.H. \& Winoto, A. Fas-mediated apoptosis and activation-induced T-cell proliferation are defective in mice lacking FADD/Mort1. Nature 392, 296-300 (1998).

92. Cusson, N., Oikemus, S., Kilpatrick, E.D., Cunningham, L. \& Kelliher, M. The death domain kinase RIP protects thymocytes from tumor necrosis factor receptor type 2induced cell death. The Journal of experimental medicine 196, 15-26 (2002).

93. Anderton, H. et al. RIPK1 prevents TRADD-driven, but TNFR1 independent, apoptosis during development. Cell death and differentiation (2018).

94. Berger, S.B. et al. Cutting Edge: RIP1 kinase activity is dispensable for normal development but is a key regulator of inflammation in SHARPIN-deficient mice. $J$ Immunol 192, 5476-5480 (2014).

95. Takeda, K. et al. Limb and skin abnormalities in mice lacking IKKalpha. Science 284, 313-316 (1999).

96. Li, Q. et al. IKK1-deficient mice exhibit abnormal development of skin and skeleton. Genes \& development 13, 1322-1328 (1999).

97. Li, Q., Van Antwerp, D., Mercurio, F., Lee, K.F. \& Verma, I.M. Severe liver degeneration in mice lacking the IkappaB kinase 2 gene. Science 284, 321-325 (1999).

98. Tanaka, M. et al. Embryonic lethality, liver degeneration, and impaired NF-kappa B activation in IKK-beta-deficient mice. Immunity 10, 421-429 (1999).

99. Rudolph, D. et al. Severe liver degeneration and lack of NF-kappaB activation in NEMO/IKKgamma-deficient mice. Genes \& development 14, 854-862 (2000).

100. Bonnard, M. et al. Deficiency of T2K leads to apoptotic liver degeneration and impaired NF-kappaB-dependent gene transcription. The EMBO journal 19, 4976-4985 (2000).

101. Moulin, M. et al. IAPs limit activation of RIP kinases by TNF receptor 1 during development. The EMBO journal 31, 1679-1691 (2012).

102. Peltzer, N. et al. HOIP deficiency causes embryonic lethality by aberrant TNFR1mediated endothelial cell death. Cell reports 9, 153-165 (2014).

103. Reiley, W.W. et al. Regulation of T cell development by the deubiquitinating enzyme CYLD. Nature immunology 7, 411-417 (2006).

104. Massoumi, R., Chmielarska, K., Hennecke, K., Pfeifer, A. \& Fassler, R. Cyld inhibits tumor cell proliferation by blocking Bcl-3-dependent NF-kappaB signaling. Cell 125, 665-677 (2006).

105. Turer, E.E. et al. Homeostatic MyD88-dependent signals cause lethal inflamMation in the absence of A20. The Journal of experimental medicine 205, 451-464 (2008).

106. Lee, E.G. et al. Failure to regulate TNF-induced NF-kappaB and cell death responses in A20-deficient mice. Science 289, 2350-2354 (2000). 


\section{Figure legends}

Figure 1: Gene activation and cell death regulation by TNFR1-SC in mammals. Engagement of tumor necrosis factor (TNF) receptor 1 (TNFR1) by TNF induces formation of the TNFR1 signaling complex (TNFR1-SC) in which the kinase-containing functional units Transforming growth factor- $\beta$-activated kinase 1 (TAK1) and TAK1-binding protein 2 and 3 (TAK1/TAB2/3) and the Inhibitor of nuclear factor kappa-B kinase subunit alpha, beta and NFkappa-B essential modulator (IKKa/IKKß/NEMO), respectively induce activation of mitogenactivated protein kinases (MAPKs)- and nuclear factor k-light-chain-enhancer of activated $B$ cells (NF- $\square$ B)-mediated expression of survival genes and proinflammatory cytokines (left panel). Apart from this activity, these two kinase complexes act together with the kinases TANK Binding Kinase 1 (TBK1)/IKK $\square$ to keep the kinase activity of Receptor interacting protein kinase 1 (RIPK1) in check. In addition, the MAP kinase-activated protein kinase 2 (MK2) regulates RIPK1 phosphorylation in the cytoplasm to prevent RIPK1 from going into cell death complexes. Ubiquitination events by cellular Inhibitor of Apoptosis (IAPs) and the Linear Ubiquitin chain assembly complex (LUBAC) as well as deubiquitination events by CYLD (cylindromatosis) and deubiquitinase with LINear linkage specificity (OTULIN) are important for the regulation of gene activation and cell death. The cell death complex or complex II can contain TNFRSF1A Associated Via Death Domain (TRADD), RIPK1, Fas-Associated DD (FADD), caspase-8/10 and RIPK3. In the canonical necroptosis pathway, when Caspase-8 activity is completely absent, RIPK1/RIPK3 signaling is unchecked. The kinase activities of RIPK1 and RIPK3 allow their stable oligomerization via their RIPK homotypic interaction motif (RHIM) domains and subsequent RIPK3 autophosphorylation and activation. Alternatively, other RHIM-containing proteins, such as DNA sensors such as DNA-induced activator of IFN (DAI, also known as ZBP1), can activate RIPK3 in the non-canonical necroptosis pathway, independently of RIPK1. Activated RIPK3 recruits mixed lineage kinase domain-like (MLKL) and induces its phosphorylation. MLKL then undergoes a conformational change leading to rupture of the plasma membrane and induction of necroptosis.

Figure 2: Role of RIPK3 in necroptosis and apoptosis regulation in mice. a) A point mutation in D161 renders the Receptor interacting protein kinase 3 (RIPK3) catalytic inactive and prevents necroptosis induction. This mutation induces a conformational change that activates RIPK1 to induce caspase-8/FADD-mediated apoptosis (left panel). Yet, if RIPK1 is lost, D161N mutant RIPK3 is able to activate a wild-type copy of RIPK3 to induce necroptosis. b) A point mutation in K51 also renders RIPK3 catalytic inactive but without affecting its scaffolding functions. Therefore, this mutation does not activate RIPK1-mediated apoptosis whilst blocking necroptosis. c) Upon loss of the cellular Inhibitor of Apoptosis 1 and 2 (clAP1/2) 
or the Transforming growth factor- $\beta$-activated kinase 1 (TAK1), the scaffolding function RIPK3 plays a role in RIPK1-mediated apoptosis.

Figure 3: Control on RIPK1-mediated proinflammatory signaling in mice. a) The three kinase complexes, Inhibitor of nuclear factor $\square$-B kinase subunits $\alpha, \beta$ and NF- $\square$ B essential modulator (IKKa/IKKß/NEMO), TANK-Binding Kinase 1 (TBK1) and IKKE and MAP kinaseactivated protein kinase 2 (MK2) are essential to prevent RIPK1-autophosphorylation and the pro-death function of RIPK1 (left panel). When any of the three checkpoints fail, RIPK1 induces cell death (right panel). b) The Linear UBiquitina chain Assembly complex (LUBAC), caspase-8 (C8) and the Receptor Interacting protein 3 (RIPK3, R3) act in concert to regulate RIPK1-mediated proinflammatory signaling (left panel). In the absence of Ripk3, Casp8 and the heme-oxidized IRP2 ubiquitin ligase 1 (Hoil-1), RIPK1 induces embryonic lethality due to induction of proinflammatory cytokines and defective hematopoiesis (left panel). When, instead of Ripk3, mixed lineage kinase domain-like (MIkl) is absent together with Hoil-1 and Casp8, RIPK3 is able to keep RIPK1 in check to allow embryogenesis, yet it is not sufficient to block lethal inflammation during adulthood (middle panel). In the absence of Ripk3 and Casp8, LUBAC is sufficient to prevent RIPK1-mediated embryonic lethality and to allow survival during adulthood. Yet, it is not sufficient to fully prevent RIPK1-mediated proinflammatory cytokines (right panel). 


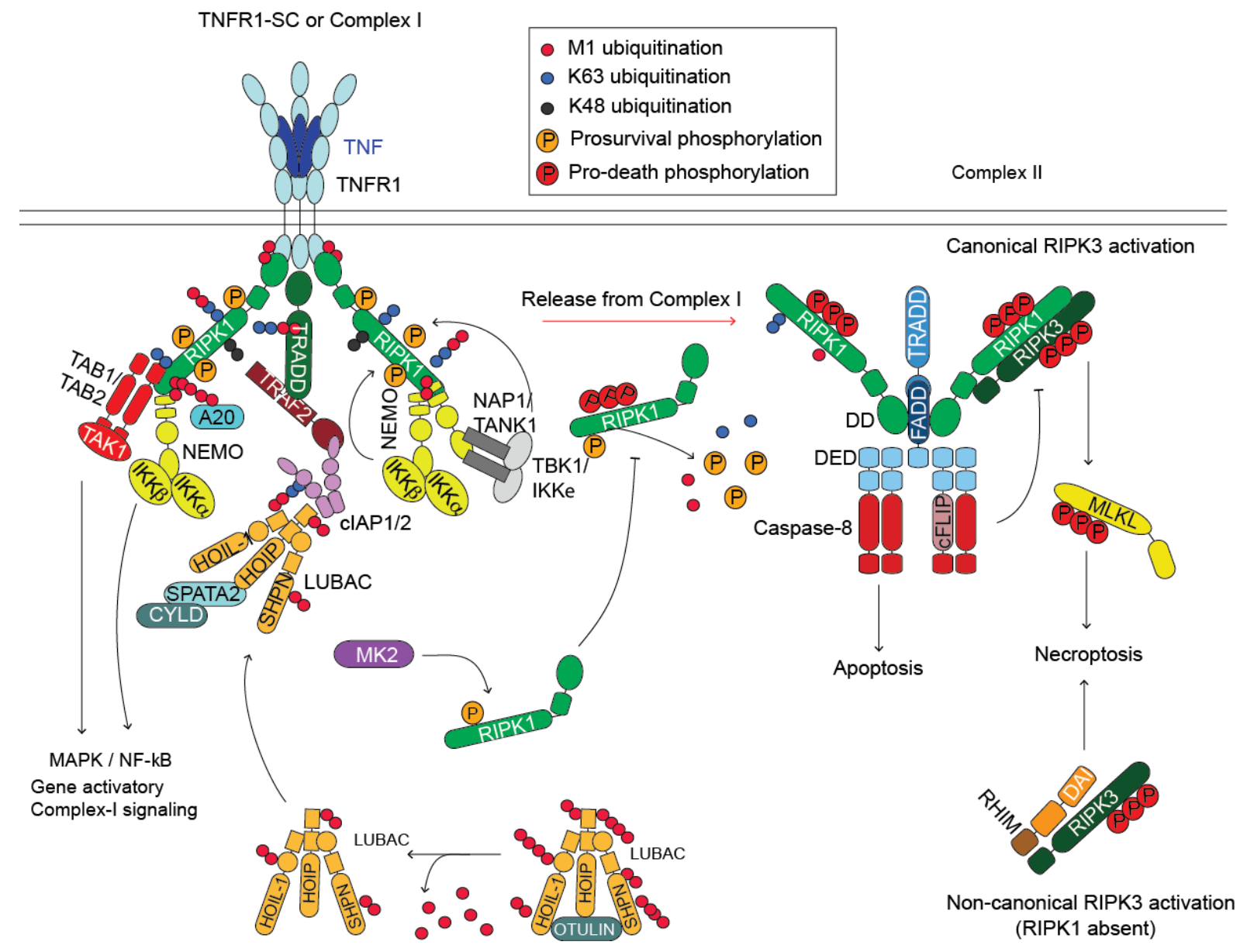

Figure 1

a

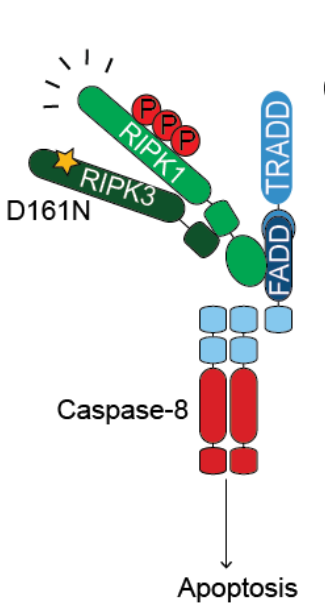

b

Loss of RIPK1

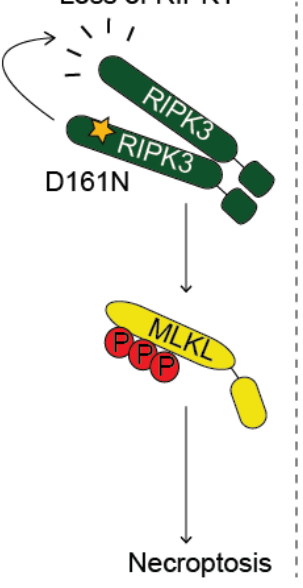

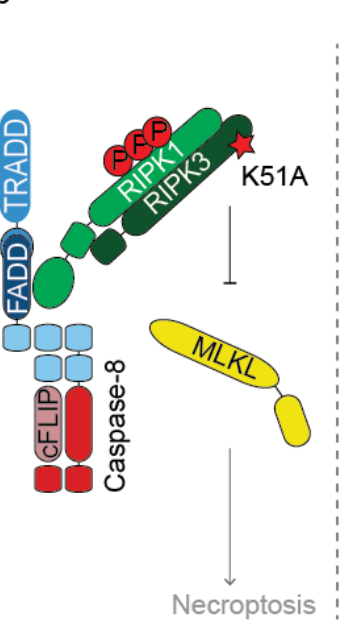

C

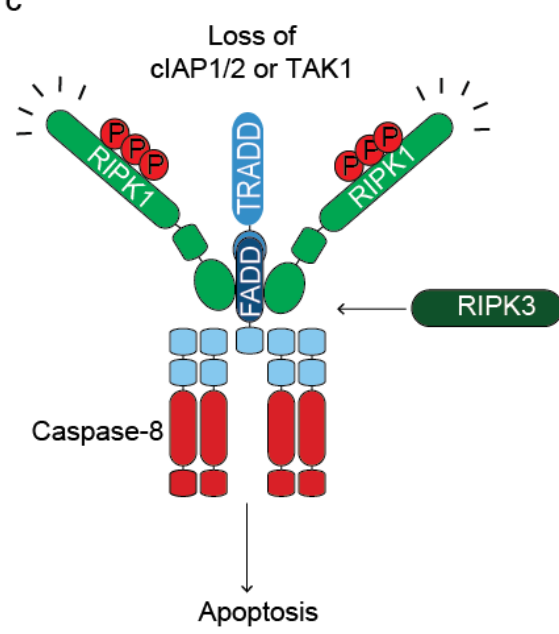

Figure 2 


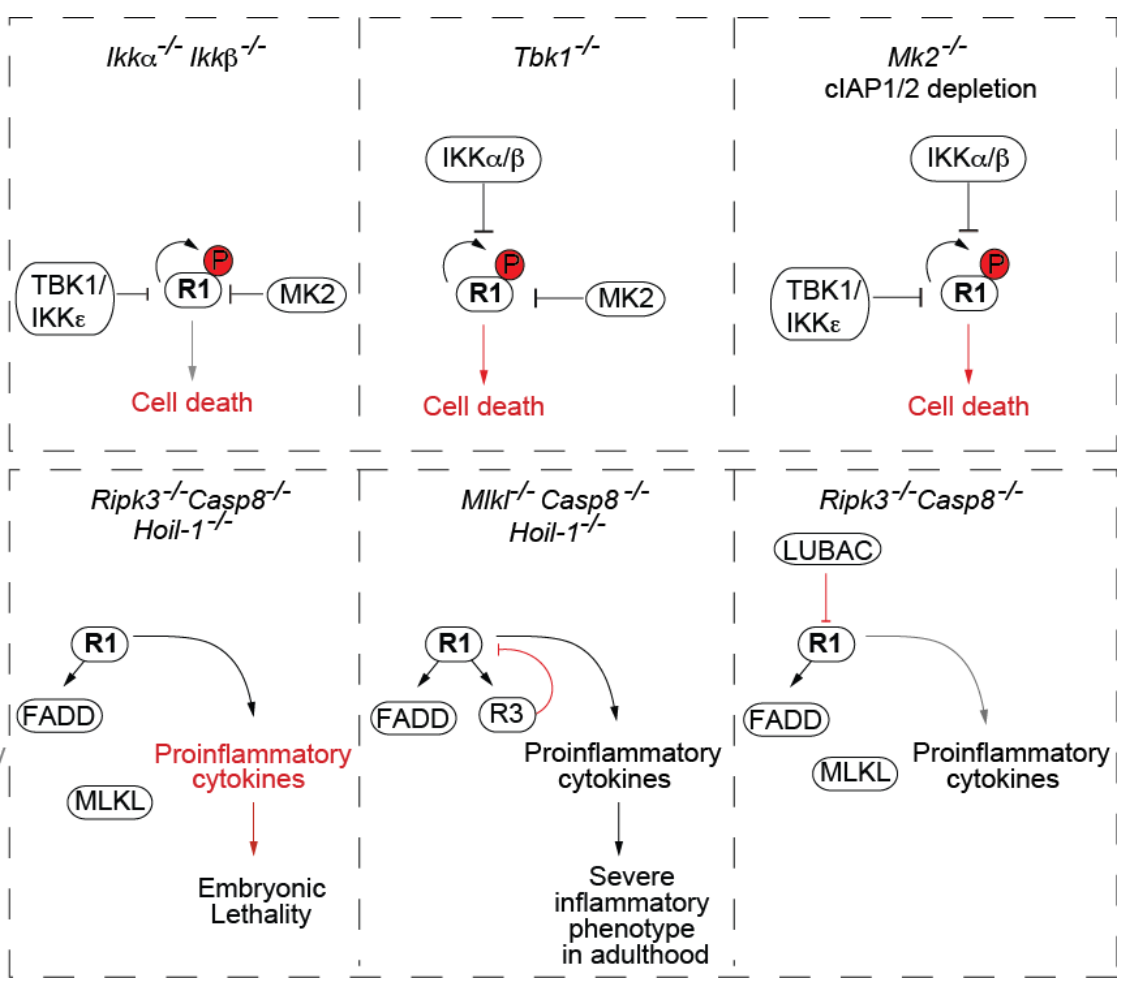

Figure 3 